\title{
VITOR PEREIRA RODRIGUES
}

Uso tópico de hidrocortisona no controle da dor e edema pós-operatório em cirurgias para remoção de terceiros molares: estudo clínico, cruzado, randomizado, duplo cego, grupo controle

São Paulo 

VITOR PEREIRA RODRIGUES

Uso tópico de hidrocortisona no controle da dor e edema pós-operatório em cirurgias para remoção de terceiros molares: estudo clínico, cruzado, randomizado, duplo cego, grupo controle

\section{Versão Corrigida}

Dissertação apresentada à Faculdade de Odontologia da Universidade de São Paulo, pelo Programa de Pós-Graduação em Ciências Odontológicas para obter o título de Mestre em Ciências Odontológicas.

Área de concentração: Cirurgia e Traumatologia Buco-Maxilo-Faciais

Orientador: Profa. Dra. Maria da Graça Naclério-Homem

São Paulo

2016 
Autorizo a reprodução e divulgação total ou parcial deste trabalho, por qualquer meio convencional ou eletrônico, para fins de estudo e pesquisa, desde que citada a fonte.

Catalogação-na-Publicação

Serviço de Documentação Odontológica

Faculdade de Odontologia da Universidade de São Paulo

Rodrigues, Vitor Pereira.

Uso tópico de hidrocortisona no controle da dor e edema pós-operatório em cirurgias para remoção de terceiros molares: estudo clínico, cruzado, randomizado, duplo cego, grupo controle / Vitor Pereira Rodrigues ; orientador Maria da Graça Naclério Homem. -- São Paulo, 2016.

89 p. : fig., tab., graf.; $30 \mathrm{~cm}$.

Dissertação (Mestrado) -- Programa de Pós-Graduação em Ciências Odontológicas. Área de Concentração: Cirurgia e Traumatologia Buco-MaxiloFaciais. -- Faculdade de Odontologia da Universidade de São Paulo.

Versão corrigida

1. Hidrocortisona. 2. Dor pós-operatória. 3. Edema. 4. Terceiro molar. 5. Cirurgia Bucal. I. Homem, Maria da Graça Naclério. II. Título. 
Rodrigues VP. Uso tópico de hidrocortisona no controle da dor e edema pósoperatório em cirurgias para remoção de terceiros molares: estudo clínico, cruzado, randomizado, duplo cego, grupo controle. Dissertação apresentada à Faculdade de Odontologia da Universidade de São Paulo para obtenção do título de Mestre em Ciências Odontológicas.

Aprovado em: $15 / 12 / 2016$

\section{Banca Examinadora}

Prof(a). Dr(a). Maria Cristina Zindel Deboni

Instituição: Faculdade de Odontologia da Universidade de São Paulo - FOUSP. Julgamento: Aprovado.

Prof(a). Dr(a). Ricardo Pelletti Ocaña

Instituição: Polícia Militar do Estado de São Paulo - PMESP.

Julgamento: Aprovado.

Prof(a). Dr(a). Marcelo Minharro Ceccheti

Instituição: Hospital das Clínicas da Faculdade de Medicina da Uversidade de São Paulo - HCFMUSP.

Julgamento: Aprovado. 



\section{DEDICATÓRIA}

À minha esposa Maria Gabriela Siqueira de Andrade Berti Rodrigues, por me apoiar em minhas decisões pessoais e profissionais, pelo companheirismo, carinho e por me encorajar nos momentos em que minha vontade, paciência e perseverança titubearam. Por aceitar e compreender minha ausência, desde a época da residência no Hospital das Clínicas até hoje e principalmente, por comemorar e dividir comigo as vitórias e derrotas da vida. Os frutos que iniciamos a colher há pouco tempo, foram plantados há muito e com certeza, juntos, muito ainda está por vir.

À minha mãe Marli Pereira Rodrigues, exemplo de garra e força. Pelas noites mal dormidas, pelo trabalho exaustivo sete dias por semana para me proporcionar a oportunidade de estar aqui, hoje, escrevendo essa dedicatória. Por todo afeto, carinho, dedicação e confiança em mim depositados. Esse é mais um passo, mais uma pequena vitória nossa.

Ao meu avô Geraldo Pereira Rodrigues (in memorian) e minha avó Noemia Aparecida Rodrigues. Peças fundamentais na minha formação pessoal e profissional, exemplos de perseverança, humildade, trabalho e dedicação à família. 



\section{AGRADECIMENTOS}

À Prof. Dra. Maria da Graça Naclério-Homem, por ter aberto as portas da Universidade de São Paulo para mim, ter me acolhido e confiado no meu trabalho. Pela orientação na realização dessa pesquisa, sua liderança e dedicação à pósgraduação, pela sua atenção e cuidado aos pacientes.

À Prof. Dra. Maria Cristina Zindel Deboni, pela sua dedicação e entusiasmo com todos os alunos da pós-graduação e por ter feito com que eu me sentisse um deles, desde o início do estágio na clínica de pós-graduação.

Ao Prof. Dr. Marcelo Minharro Cecchetti, pelos ensinamentos e confiança depositados em mim e em meu trabalho desde meu início na Cirurgia Bucomaxilofacial durante a residência no Hospital das Clínicas, pela orientação e ajuda na elaboração do projeto de pesquisa e principalmente pela amizade, incentivo e conselhos, não só em minha vida profissional, mas também pessoal.

Aos colegas de pós-graduação Ricardo, Yuri, Alex, Milton, Natacha, Natália, Daniel, Ana Paula, Matheus, Rubens e Marcelo pela ajuda e companhia durante a etapa de realização dos créditos, clínicas e por tornarem todo esse tempo mais leve e descontraído.

A todos os docentes da disciplina de Cirurgia e Traumatologia Buco-MaxiloFaciais da Faculdade de Odontologia da USP pelo convívio e ensinamentos ao longo do curso.

Aos funcionários do Departamento de Cirurgia, Prótese e Traumatologia Buco-Maxilo-Faciais, em especial Sr. Édison Henrique Vicente e Sra. Aparecida Conceição de Souza, pela ajuda, colaboração em cumprir os prazos e nos manter na linha.

Aos meus amigos e familiares, dos quais me ausentei parcialmente durante a realização do curso e desse trabalho. 

"...não ser útil a ninguém é realmente nada valer..." René Descartes - Discurso do Método 



\section{RESUMO}

Rodrigues VP. Uso tópico de hidrocortisona no controle da dor e edema pósoperatório em cirurgias para remoção de terceiros molares: estudo clínico, cruzado, randomizado, duplo cego, grupo controle [dissertação]. São Paulo: Universidade de São Paulo, Faculdade de Odontologia; 2016. Versão Corrigida.

A exodontia de terceiros molares pode afetar significativamente a qualidade de vida dos pacientes no período pós-operatório. A resposta inflamatória gerada pelo dano tecidual inerente ao procedimento pode apresentar edema e dor de duração e intensidade variáveis. No presente estudo foi avaliada a eficácia do corticosteroide hidrocortisona, como solução de irrigação durante exodontias de terceiros molares no controle do edema e da dor pós-operatória. Vinte e oito pacientes foram incluídos no estudo e após randomização foram submetidos a exodontia de ambos os terceiros molares inferiores em tempos cirúrgicos distintos, pelo mesmo cirurgião. Foram distribuídos aleatoriamente para receber $250 \mathrm{ml}$ de solução contendo $500 \mathrm{mg}$ de hidrocortisona (grupo $\mathrm{H}$ ) ou $250 \mathrm{ml}$ de solução salina a $0,9 \%$ (grupo $\mathrm{C}$ ). Para avaliação da eficácia da hidrocortisona no controle da dor pós-operatória três mensurações foram utilizadas: a quantidade de medicação analgésica de resgate consumida, o tempo entre o término da cirurgia e o uso do primeiro comprimido de resgate e a EVA em seis momentos. Para aferição da eficácia da hidrocortisona no controle do edema foram criadas 3 medidas faciais e o edema foi medido por meio da diferença em milímetros entre o segundo dia de pós-operatório e o préoperatório. A comparação entre os grupos mostrou que a hidrocortisona foi eficaz no controle pós-operatório do edema em duas das medidas aferidas. A dor acompanhou a diminuição do edema, sendo que na média a EVA foi menor no grupo $\mathrm{H}$, no entanto não houve diferença estatisticamente significativa nas outras duas aferições de dor. Conclui-se que a utilização local da hidrocortisona, como solução de irrigação trans-operatória em exodontias de terceiros molares é efetiva na redução do edema e da percepção de dor pós-operatória.

Palavras-chave: Hidrocortisona. Dor pós-operatória. Edema. Terceiro Molar. Cirurgia Bucal. 



\begin{abstract}
Rodrigues VP. Topical hydrocortisone for pain and edema control after third molar surgery: a clinical, crossover, randomized, double-blind, controlled study [dissertation]. São Paulo: Universidade de São Paulo, Faculdade de Odontologia; 2016. Versão Corrigida.
\end{abstract}

The third molar removal can significantly affect the quality of life of patients in the postoperative period. The inflammatory response caused by tissue damage inherent to the procedure may include edema and pain with variable duration and intensity. In the present study, we evaluated the efficacy of hydrocortisone as irrigation solution during third molars removal for postoperative pain and edema control. Twenty-eight patients were included in the study after randomization and were subjected to removal of both mandibular third molars in different surgical times by the same surgeon. They were randomly assigned to receive $250 \mathrm{ml}$ solution containing $500 \mathrm{mg}$ of hydrocortisone (group $\mathrm{H}$ ) or $250 \mathrm{ml} 0.9 \%$ saline solution (group C). To evaluate the efficacy of hydrocortisone in controlling postoperative pain three measurements were applied: the amount of analgesic medication taken, the time between the end of surgery and the use of the first analgesic tablet and VAS in six moments. To measure the effectiveness of hydrocortisone in edema control three facial measurements were created and swelling was measured by the difference in millimeters between the second postoperative day and preoperative. The comparison between the groups showed that hydrocortisone was effective in postoperative edema control in two of the measurements taken. Pain accompanied the edema reduction and the average VAS was lower in $\mathrm{H}$ group, however there was no statistically significant difference in the other two measurements of pain. We concluded that the local use of hydrocortisone as intraoperative irrigation solution for third molar removal is effective in reducing postoperative edema and pain perception.

Keywords: Hydrocortisone. Postoperative pain. Edema. Third Molar. Oral surgery. 



\section{LISTA DE ILUSTRAÇÕES}

Figura 4.1 - Soluções teste e controle

Figura 4.2 - Reprodução esquemática dos pontos e medidas realizadas na face dos pacientes.

Gráfico 5.1 - Distribuição de impacção dental nos grupos Hidrocortisona e Controle .52

Gráfico 5.2 - Distribuição da quantidade de cirurgias entre os grupos, de acordo com a classificação de dificuldade cirúrgica

Gráfico 5.3 - Distribuição das respostas quanto ao pior pós-operatório entre os grupos. 56

Gráfico 5.4 - Valores médios de EVA e respectivos erros padrões segundo grupo Hidrocortisona (anti-inflamatório) e Controle, momento de avaliação e ordem de aplicação (primeira cirurgia utilizando hidrocortisona ou soro fisiológico) 



\section{LISTA DE TABELAS}

Tabela 5.1 - Descrição da amostra em gênero (distribuição e porcentagem), idade (média, mediana e desvio padrão), lado da primeira cirurgia (distribuição e porcentagem) e intervalo de tempo entre as cirurgias wash out (média, mediana e desvio padrão)

Tabela 5.2 - Descrição do grau dificuldade cirúrgica entre os grupos, e resultado do teste comparativo

Tabela 5.3 - Descrição da duração do tempo cirúrgico em minutos (média, desvio padrão, mediana, mínimo e máximo) e resultado do teste comparativo entre os grupos

Tabela 5.4 - Descrição da ocorrência de sangramento entre os grupos e teste comparativo .54

Tabela 5.5 - Descrição da variação das medidas de edema (t1 - t0) em milímetros entre os grupos, e resultado do teste comparativo .55

Tabela 5.6 - Descrição da quantidade de comprimidos de dipirona consumidos, intervalo de tempo entre término da cirurgia e uso da primeira dipirona e resultado do teste comparativo .56

Tabela 5.7 - Comparações múltiplas da EVA entre grupos 58

Tabela 5.8 - Resultado das correlações de Spearman entre a escala de dificuldade cirúrgica, EVA e edema. 



\section{LISTA DE ABREVIATURAS E SIGLAS}

$\mathrm{Ag}$

AINE

$\mathrm{Cl}$

Co

dp

EVA

$\mathrm{mg}$

$\mathrm{ml}$

$\min$

$\mathrm{mm}$

PVPI

$\mathrm{Tr}$

VAS

AAOMS

NICE

$\mathrm{H}$

C

Ângulo goníaco

Anti-inflamatório não esteroidal

Comissura labial

Canto do olho

desvio padrão

Escala Visual Analógica

miligramas

mililitros

minutos

milímetros

lodopovidona

Trágus

Visual Analogic Scale

American Association of Oral and Maxillofacial Surgeons

National Institute for Health and Care Excellence

Hidrocortisona

Controle 



\section{LISTA DE SÍMBOLOS}

$\begin{array}{ll}\% & \text { Por cento (porcentagem) } \\ > & \text { Maior que } \\ < & \text { Menor que } \\ = & \text { Igual a } \\ \leq & \text { Menor ou igual a }\end{array}$





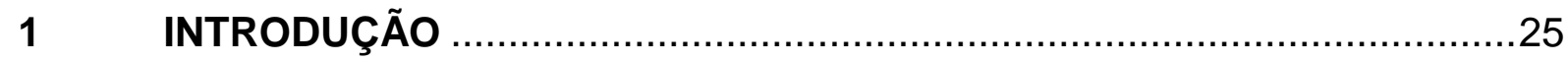

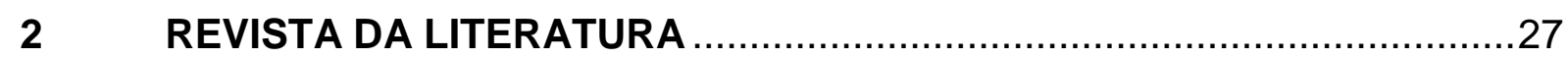

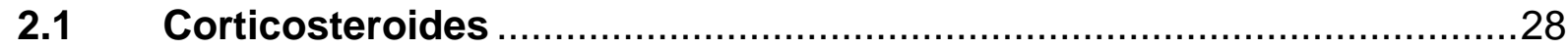

2.2 Uso dos corticosteroides em Cirurgia Buco-Dento-Alveolar .................29

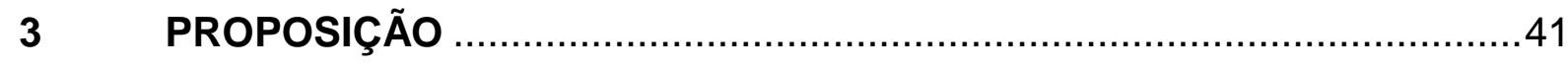

4 CASUÍSTICA - MATERIAL E MÉTODOS ........................................... 43

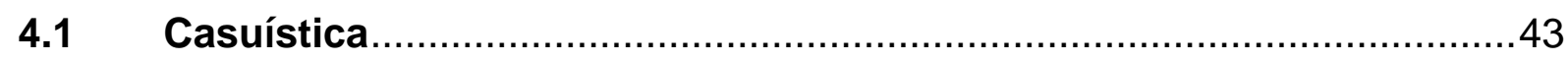

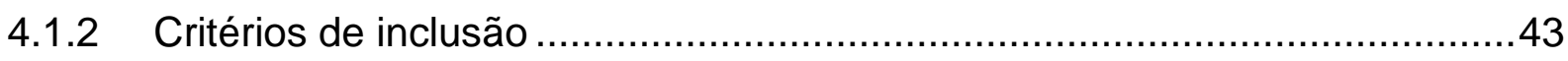

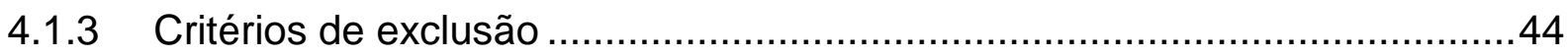

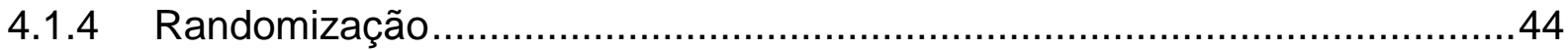

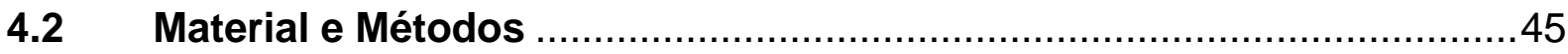

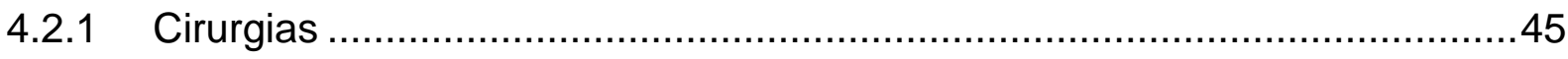

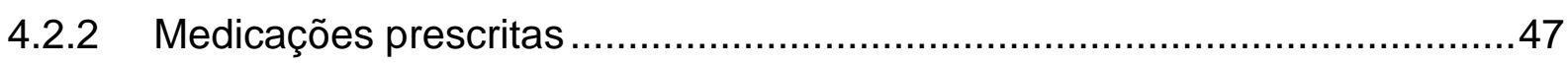

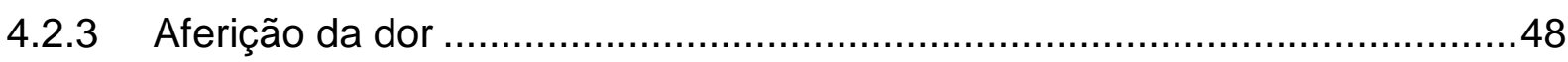

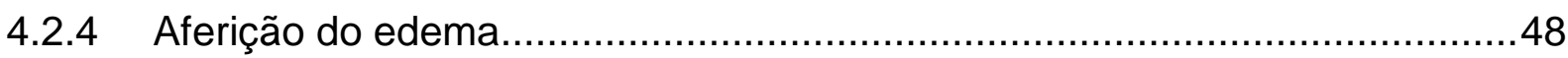

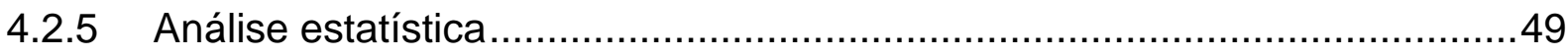

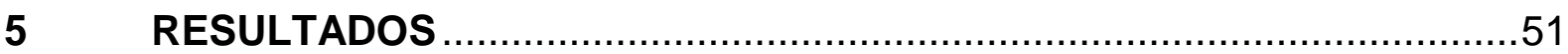

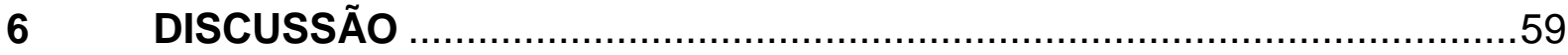

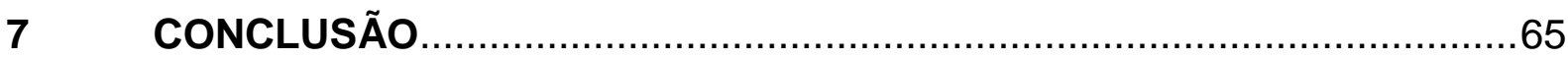

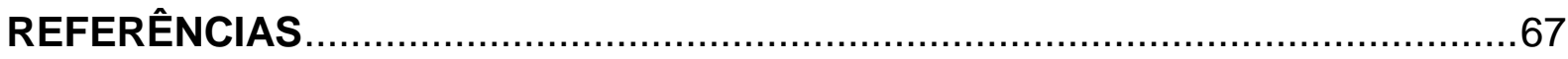

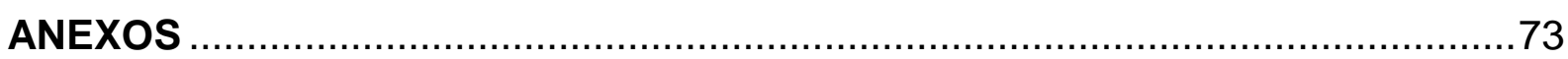





\section{INTRODUÇÃO}

Os terceiros molares são os dentes com maior prevalência de falha na erupção, e a cirurgia para remoção destes é um dos procedimentos mais comumente realizados pelo Cirurgião Bucomaxilofacial. Na maioria dos casos são cirurgias de pequeno porte, no entanto fatores como idade do paciente, grau de impacção dentária e experiência do cirurgião podem influenciar no ato cirúrgico e consequentemente na resposta inflamatória, podendo causar um pós-operatório desconfortável, acompanhado de dor e edema de intensidades variáveis e que podem influenciar significativamente na qualidade de vida dos pacientes (Baqain et al., 2008; Bello et al., 2011; Mettes et al., 2012).

Com intuito de proporcionar um período pós-operatório mais confortável e contribuir para que os pacientes retornem mais rapidamente às suas atividades diárias, diversas drogas, posologias e vias de administração foram estudadas, principalmente os fármacos com atividade anti-inflamatória, dentre estes os corticosteroides são os que apresentam melhores resultados.

Dentre as vias de administração de corticosteroides utilizadas em cirurgias buco-dento-alveolares, a via oral é a mais comum, no entanto esta depende da adesão do paciente ao tratamento e pode estar contraindicada em situações específicas como em indivíduos que apresentam doenças gástricas. Assim as vias intramuscular, endovenosa, submucosa e tópica foram testadas em diversos trabalhos e mostraram resultados conflitantes em relação à superioridade de uma em relação a outra. Vale ressaltar que a via endovenosa pode ser considerada uma das melhores opções quando a cirurgia é realizada em âmbito hospitalar, sob anestesia geral, pois além de proporcionar bons resultados no controle da dor e edema pós-operatório é eficaz também no controle da náusea e vômito. No entanto, salvo situações específicas como dentes com impacções profundas e risco de fratura mandibular, no Brasil a grande maioria dessas cirurgias são realizadas em âmbito ambulatorial, sob anestesia local, tanto na esfera pública quanto privada. 
Assim, propusemo-nos a desenvolver um ensaio clínico com intuito de testar a via de administração tópica do corticosteroide hidrocortisona, como solução de irrigação trans-operatória, pois essa via de administração, além de ser de baixo custo e não adicionar novas etapas ao ato cirúrgico, pode contribuir para uma melhora na qualidade de vida no período pós-operatório dos pacientes submetidos à exodontia de terceiros molares. 


\section{REVISTA DA LITERATURA}

A remoção de dentes inclusos, principalmente de terceiros molares, é um dos procedimentos cirúrgicos mais comumente realizados pelo Cirurgião-Dentista especialista em Cirurgia e Traumatologia Bucomaxilofacial (Baqain et al., 2008). Os terceiros molares são os dentes com maior prevalência de falha na erupção, na maior parte dos casos encontram-se impactados na face distal dos segundos molares, podendo apresentar-se assintomáticos ou não (Mettes et al., 2012).

A necessidade de realizar a exodontia de terceiros molares impactados e assintomáticos é controversa, a Associação Americana de Cirurgiões Orais e Maxilofaciais (AAOMS, 2013) indica que a remoção desses dentes deve ser realizada de forma profilática, pois representam uma entidade com real potencial patológico, e que a exodontia precoce proporcionaria um pós-operatório menos desconfortável aos pacientes. Antagonicamente, o Sistema Nacional de Saúde Britânico (NICE, 2000), sugere que os terceiros molares impactados e assintomáticos devam ser proservados e contraindica a exodontia profilática, sob a alegação de que o índice de complicações pós-operatórias e o custo desses procedimentos para o sistema público de saúde britânico se sobrepõem aos benefícios, uma vez que a ocorrência de doenças associadas aos dentes impactados e assintomáticos é pequena. Mettes et. al (2012) em uma revisão sistemática, concluiu que não existe evidência científica que suporte ou refute a prática rotineira de exodontia profilática de terceiros molares impactados e assintomáticos. Dessa forma, cabe ao cirurgião ter bom senso nas indicações cirúrgicas e quando optado pelo acompanhamento este deve ser feito de maneira clínica, radiográfica e periódica.

Independente de qual corrente o cirurgião siga, a exodontia de terceiros molares impactados, assintomáticos ou não, em sua maioria são cirurgias de porte pequeno, no entanto é um procedimento que gera desconforto pós-operatório ao paciente de grau e intensidade variáveis, que pode afetar a qualidade de vida do indivíduo neste período (McGrath et al., 2003). Sequelas da cirurgia são provenientes de perturbações do processo inflamatório tecidual normal, podendo 
haver presença de um ou mais sinais cardinais que incluem dor, calor, rubor, aumento de volume e perda de função, sendo que o trismo, dor e edema são os mais comumente relatados. Diversos fatores apresentam efeito significativo na ocorrência de complicações após o procedimento cirúrgico e podem estar relacionados com a idade do paciente, gênero, hábitos, e uso de medicações. Associados a anatomia cirúrgica como nível de impacção dentária, angulação, presença de inflamação prévia, relação com o nervo alveolar inferior e densidade óssea. Além de fatores que dependem do próprio cirurgião, que podem aumentar o tempo e trauma cirúrgico, como experiência, habilidade e aptidão (Lopes, 1995; Baqain et al., 2008; Bello et al., 2011).

A necessidade de reduzir o desconforto pós-operatório das exodontias de terceiros molares de modo que o paciente retorne mais rapidamente às suas atividades diárias tem sido objetivo de diversos estudos, sendo que diferentes fármacos, posologias e vias de administração foram testadas, principalmente aquelas com efeito anti-inflamatório e nessa classe de medicamentos os corticosteroides são os que apresentam resultados mais eficazes (Beirne; Hollander, 1986; Tuffin et al., 1990; Deo, 2006; Graziani et al., 2006; Grossi et al., 2007; VegasBustamante et al., 2008; Antunes et al., 2011; Arakeri; Brennan, 2011; Boonsiriseth et al., 2012; Marques et al., 2014; Mahmoud Hashemi et al., 2015; Ibikunle et al., 2016).

\subsection{Corticosteroides}

Os corticosteroides e seus derivados sintéticos biologicamente ativos diferem nas suas atividades metabólicas (glicocorticoides) e de regulação de eletrólitos (mineralocorticoides). Estes agentes são empregados para terapia de reposição quando ocorre algum comprometimento da produção endógena. Além disso, os glicocorticoides são supressores potentes da inflamação e, por serem utilizados numa ampla variedade de doenças inflamatórias e autoimunes, estão entre as classes de fármacos frequentemente prescritos (Brutin et al., 2006). 
Os efeitos dos corticosteroides são amplos, incluem a manutenção do balanço hidroeletrolítico, carboidratos, metabolismo lipídico e proteico, preserva a função dos sistemas cardiovascular, imunológico, endócrino, nervoso e também dos rins e músculos esqueléticos. Além de proporcionar ao organismo a capacidade adaptativa em situações de estresse como estímulos nocivos ao corpo e mudanças ambientais (Shaikh et al., 2012).

Os corticosteroides atuam na redução da resposta inflamatória por meio da inibição da enzima fosfolipase A2, envolvida na conversão de fosfolipídios em ácido araquidônico, por conseguinte, bloqueiam a síntese de outros produtos como as prostaglandinas, leucotrienos e substâncias relacionadas ao tromboxano. Em essência, os corticosteroides evitam a formação desses produtos finais da cascata de inflamação, que são potentes mediadores inflamatórios e fazem com que os sinais cardinais do processo inflamatório se instalem. Atuam também inibindo a diapedese, ou seja, o extravasamento de fluídos e proteínas plasmáticas dos vasos capilares para o espaço intersticial e estabilizam a membrana das células lisossômicas que possuem grande quantidade de enzimas hidrolíticas. Além de reduzir a formação de bradicinina, um potente vasodilatador (Brutin et al., 2006; Shaikh et al., 2012; Ngeow; Lin, 2016).

\subsection{Uso dos corticosteroides em Cirurgia Buco-Dento-Alveolar}

Uma das causas mais comuns de procura por atendimento odontológico é a dor orofacial aguda, dentre elas a dor pós-operatória. O desconforto no período pósoperatório das exodontias de terceiros molares pode variar quanto a frequência e severidade, que vão desde desconforto leve até complicações que necessitem de intervenções adicionais, podendo resultar em danos permanentes (Siqueira et al., 2004).

A primeira publicação científica que abordou a utilização de corticosteroides em odontologia é atribuída à Strean (1951). Ainda na década de 1950 Spies et al. (1952) também publicaram sua experiência com uso da cortisona no âmbito da 
odontologia. Desde então, uma ampla gama de pesquisadores vem publicando seus estudos com o uso de corticosteroides em odontologia, principalmente em cirurgia oral.

Beirne e Hollander (1986) avaliaram a eficácia de uma dose única endovenosa, de $125 \mathrm{mg}$ de metilprednisolona no controle da dor, edema e trismo após exodontia de terceiros molares. Os pacientes foram distribuídos em 2 grupos, teste e controle, baseados nos resultados encontrados os autores relataram que os pacientes do grupo experimental apresentaram dor e edema significativamente menor comparados aos do grupo controle, no entanto não houve diferença estatística em relação ao trismo pós-operatório, concluindo que a dose préoperatória endovenosa do corticosteroide foi eficaz para o controle do desconforto após exodontia de terceiros molares.

Ustün et al. (2003) também avaliaram a via endovenosa de aplicação de metilprednisolona no pré-operatório de exodontias de terceiros molares. Em um estudo cruzado, envolvendo 26 pacientes, testaram duas doses diferentes do corticosteroide. Após randomização, na primeira cirurgia o paciente recebia uma dose de 1,5mg ou $3 \mathrm{mg}$ por quilograma de peso e na segunda cirurgia a dose contrária. Avaliaram a amplitude de abertura bucal pela máxima distância interincisal dos incisivos superiores e inferiores, o edema por meio de medidas faciais e a dor pela escala visual analógica e quantidade de comprimidos analgésicos consumidos. Não encontraram diferença estatisticamente significativa entre os dois grupos, concluindo que não existe benefício em utilizar uma dose maior de metilprednisolona para controle do desconforto após a exodontia de terceiros molares.

O trabalho desenvolvido por Laureano Filho et al. (2008) também avaliou diferentes doses de corticosteroide. Foi testada a dexametasona, via oral, na dose de $4 \mathrm{mg}$ ou $8 \mathrm{mg}$, num ensaio clínico cruzado, randomizado e duplo cego. Trinta pacientes foram submetidos à exodontia de ambos os terceiros molares inferiores, em momentos diferentes, foi administrado uma das doses em cada lado, escolhidos após randomização, uma hora antes do início de cada cirurgia. Foram aferidos 0 edema por meio de medidas faciais, a dor por meio de escala visual analógica e o trismo pela distância interincisal dos dentes anteriores. Todos os pacientes receberam uma prescrição de $750 \mathrm{mg}$ de paracetamol, via oral, para ser utilizada a 
cada 6 horas durante os primeiros 4 dias de pós-operatório. Os resultados mostraram que houve diferença estatística na amplitude do edema e do trismo pósoperatório, sendo que na cirurgia em que os pacientes receberam a dose de $8 \mathrm{mg}$ de dexametasona as medidas foram significativamente menores. Já na avaliação da dor pós-operatória, o aumento da dose do corticosteroide não produziu maiores efeitos analgésicos.

Marques et al. (2014) testaram a injeção intraoral submucosa de betametasona, aplicada no pós-operatório imediato de exodontias de terceiros molares, no controle da dor, trismo e edema. Vinte e cinco pacientes foram incluídos nesse ensaio clínico, cruzado, randomizado e triplo cego. Em um dos lados da exodontia os pacientes receberam a dose de $12 \mathrm{mg}$ do corticosteroide, a outra cirurgia foi realizada num segundo tempo e serviu como controle uma vez que foi utilizada apenas injeção de solução salina a 0,9\%. Além da dose de corticosteroide ou de soro fisiológico no pós-operatório imediato, todos os pacientes receberam a prescrição de 1grama de paracetamol a cada 8 horas e como medicação de resgate $575 \mathrm{mg}$ de dipirona (metamizol), que deveria ser utilizado em caso de dor persistente. A dor foi aferida por meio de escala visual analógica e pela quantidade de comprimidos de resgate consumidos e não houve diferença estatisticamente significativa entre os grupos. Em relação ao trismo e edema, foram avaliados, respectivamente, por meio da máxima distância interincisal dos incisivos centrais superiores e inferiores e de medidas faciais pré e pós-operatórias, sendo que em tais parâmetros, o corticosteroide também não foi efetivo e não mostrou resultados estatisticamente significantes.

Outro trabalho que também avaliou a eficácia da injeção intraoral submucosa de corticosteroide foi de Grossi et al. (2007). Neste estudo foram incluídos 61 pacientes, divididos em 3 grupos, após aplicação de anestesia local, receberam uma dose trans-operatória de $8 \mathrm{mg}$ ou $4 \mathrm{mg}$ de dexametasona e os do grupo controle não receberam nenhum tipo de medicação trans-operatória. Todos os pacientes receberam uma associação de $500 \mathrm{mg}$ de paracetamol e $30 \mathrm{mg}$ de codeína, em comprimido, no pós-operatório imediato e foram orientados a fazer uso da mesma medicação em caso de dor. Encontraram que o pico de edema, em todos os grupos se deu no segundo dia de pós-operatório, sendo que ambos os grupos que receberam dexametasona apresentaram edema significativamente menor que o 
controle, no entanto não houve diferença entre os 2 grupos teste, em relação ao trismo e a dor não relataram diferença entre os grupos. Além desses três parâmetros também foi aplicado um questionário denominado Escala de Severidade de Sintomas Pós-operatórios, com intuito de avaliar a percepção dos pacientes em relação à qualidade de vida após a exodontia. Os pacientes que não receberam o corticosteroide reportaram maior alteração na percepção quanto à aparência facial, nos demais parâmetros não houve diferença estatisticamente significativa.

Ibikunle et al. (2016) compararam a aplicação de $40 \mathrm{mg}$ de predinisolona pela via oral e submucosa ao controle, em um estudo envolvendo 186 pacientes, divididos em 3 grupos. Um questionário de qualidade de vida foi aplicado no préoperatório e pós-operatório. Os resultados mostraram que os pacientes do grupo controle apresentaram uma piora estatisticamente significativa na qualidade de vida comparados aos pacientes dos grupos teste. Já na avaliação entre os grupos teste, os pacientes que receberam a medicação pela via oral reportaram piores índices de qualidade de vida comparados à via submucosa. Os autores avaliaram também dor, trismo e edema pós-operatório, sendo que os grupos testes apresentaram em todos os três parâmetros, índices estatisticamente menores que o controle. De modo que os autores concluíram que uma dose pré-operatória de $40 \mathrm{mg}$ de predinisolona proporciona um pós-operatório significativamente melhor que o controle e que a aplicação submucosa apresentou menor alteração da qualidade de vida dos pacientes comparada à mesma dose pela via oral.

A via intramuscular foi estudada por Klongnoi et al. (2012), que aplicaram uma dose pré-operatória de $8 \mathrm{mg}$ de dexametasona no músculo deltoide de pacientes que seriam submetidos à exodontia de um terceiro molar inferior. Após um período mínimo de 30 dias o dente contralateral também foi removido, como controle, sendo aplicada $2 \mathrm{ml}$ de solução salina. Os autores avaliaram os pacientes no pós-operatório imediato, no segundo e sétimo dia de pós-operatório. A análise estatística mostrou que na cirurgia em que os pacientes receberam a dose prévia de dexametasona 0 edema foi menor apenas no segundo dia de pós-operatório. A dor apresentou índices menores no segundo e sétimo dia de pós-operatório também nos pacientes que receberam o corticosteroide, enquanto que na amplitude de abertura bucal não houve diferença entre os grupos em nenhum dos momentos avaliados. 
Ainda em relação a via intramuscular, Vegas-Bustamante et al. (2008) avaliaram a aplicação de 40mg de metilpredinisolona no músculo masseter no controle da dor, trismo e edema no pós-operatório de exodontias de terceiros molares inferiores. Os resultados mostraram que essa via de administração intramuscular intraoral também foi eficaz e mostrou resultados estatisticamente significativos em todos os três parâmetros avaliados.

Além do uso local pela injeção submucosa ou intramuscular intraoral, os corticosteroides foram aplicados localmente, direto no alvéolo após exodontia dos terceiros molares. Graziani et al. (2006) testaram a eficácia da aplicação de pó de dexametasona nos alvéolos imediatamente após as exodontias, em duas concentrações diferentes, $4 \mathrm{mg}$ e 10mg, comparando com a injeção submucosa de $4 \mathrm{mg}$ também de dexametasona. Os pacientes eram submetidos à exodontia de ambos os terceiros molares, com um intervalo mínimo de 4 semanas entre as cirurgias. Em um dos lados receberam o corticosteroide em uma das formas citadas, de acordo com o grupo a que pertencia. Enquanto que o outro lado serviu de controle, não recebendo nenhuma das formas de aplicação do corticosteroide. Neste ensaio clínico envolvendo 43 pacientes divididos em 3 grupos, de acordo com a via de administração utilizada, os resultados encontrados pelos autores mostraram que o edema foi significativamente menor em todos os grupos teste comparados ao controle, mas não houve diferença quando a comparação foi feita apenas entre os testes, mostrando que independente da dose ou via de administração, o corticosteroide foi efetivo no controle do edema. Já em relação à dor, apenas o grupo de recebeu $4 \mathrm{mg}$ de dexametasona em pó apresentou resultados estatisticamente positivos comparado ao controle, tendo apresentado índices menores de dor avaliados por meio de EVA. Já o grupo que recebeu a injeção submucosa de corticosteroide teve um pós-operatório com maiores índices de dor comparado ao controle.

Majid e Mahmood (2013) também avaliaram o uso tópico de aplicação dos corticosteroides, em forma de pó diretamente nos alvéolos após exodontia. Em um trabalho que avaliou 5 diferentes vias de administração de dexametasona buscou definir qual dessas proporcionaria um melhor conforto pós-operatório aos pacientes submetidos à exodontia de terceiros molares. Dividiram os participantes em 6 grupos, um controle e outros cinco que receberam $4 \mathrm{mg}$ de dexametasona após a 
cirurgia pela via oral, intramuscular no músculo deltoide, pela via endovenosa, submucosa ou em forma de pó aplicado diretamente no alvéolo, chamada de via endoalveolar pelos autores. Todos os pacientes receberam a prescrição de comprimidos de $50 \mathrm{mg}$ de Tramadol que deveriam ser utilizados como analgésicos de resgate. Os pacientes foram avaliados no primeiro, terceiro e sétimo dia de pósoperatório. A dor foi mensurada por meio de escala visual analógica e pela quantidade de comprimidos analgésicos de resgate consumidos, o edema por medidas faciais e o trismo pela distância entre os dentes incisivos superiores e inferiores. Quando comparados os grupos teste com o controle, apenas o grupo que recebeu a dexametasona pela via oral não apresentou resultados estatisticamente significativos em relação à dor, enquanto que os outros grupos testes relataram menos dor comparado ao controle. Na avaliação do edema e trismo todos os grupos que receberam o corticosteroide tiveram melhores resultados comparados ao controle. Na avaliação entre os grupos testes o edema foi menor no grupo que recebeu dexametasona endovenosa, seguido pela via intramuscular, submucosa, oral e endoalveolar. Em relação ao trismo a via submucosa foi mais efetiva em seu controle, já na avaliação da dor, novamente a via endovenosa foi a que apresentou melhores resultados, seguida da endoalveolar. No entanto em nenhum dos três parâmetros essas diferenças observadas tiveram relevância estatística. De modo que os autores concluíram que pela eficácia apresentada, essas vias de administração local podem ser uma alternativa em situações específicas e ressaltam que o uso no pós-operatório imediato, próximo ao sítio cirúrgico pode ser uma boa opção em cirurgias que geraram maior dificuldade trans-operatória do que o previamente planejado.

Buscando outra opção para o uso local dos corticosteroides no controle do desconforto pós-operatório em exodontias de terceiros molares, Bhargava et al. (2014) propuseram o uso de $4 \mathrm{mg}$ de dexametasona em uma solução contendo o corticosteroide associado ao anestésico local lidocaína com adrenalina na concentração de 1:50.000. A solução chamada pelos autores de Twin mix foi utilizada para o bloqueio pterigomandibular e comparada com as vias de administração oral, injeção submucosa no vestíbulo bucal, endovenosa, intramuscular no músculo deltoide. O grupo controle não recebeu corticosteroide. Foram realizadas comparações entre os grupos testes e destes com o grupo 
controle. Os resultados mostraram que todos os grupos que receberam 0 corticosteroide apresentaram índices menores de trismo, dor e edema comparados ao controle, mas não houve diferença significativa entre os grupos testes, sendo que todos apresentaram resultados clínicos similares.

Ainda no escopo da Cirurgia e Traumatologia Bucomaxilofacial, os corticosteroides foram utilizados localmente por Pourdanesh et al. (2014) como solução de irrigação, não em exodontias mas durante osteotomias sagitais do ramo mandibular, em cirurgias ortognáticas. Os autores realizaram um estudo cruzado, randomizado, envolvendo 18 pacientes. Em um dos lados da osteotomia, após a visualização do nervo alveolar inferior, foi realizada irrigação com solução de $1 \mathrm{ml}$ contendo $4 \mathrm{mg}$ de dexametasona e a mesma quantidade foi irrigada no momento da fixação da osteotomia. No lado contralateral foi utilizada irrigação com solução fisiológica a 0,9\% como controle. A hipótese dos autores era de que a irrigação com a solução teste favoreceria o retorno mais rápido da sensibilidade da área inervada pelo nervo alveolar inferior, uma vez que a parestesia dessa região é uma sequela comum observada após a osteotomia sagital do ramo mandibular. Por meio de testes subjetivos e objetivos a sensibilidade foi mensurada 24 e 72 horas após a cirurgia, 1 semana, 3 semanas, 6 semanas, 8 semanas e 6 meses de pósoperatório, sendo que em nenhuma dessas avaliações houve diferença estatística entre os grupos, levando os autores a conclusão de que não existe vantagem no uso local da dexametasona, como solução de irrigação trans-operatória, no retorno da sensibilidade após cirurgia ortognática mandibular.

Além do uso de corticosteroides, outros métodos e fármacos foram propostos e estudados também com intuito de proporcionar aos indivíduos submetidos à exodontia de terceiros molares um pós-operatório mais confortável. Tuffin et al. (1990) avaliaram a eficácia da irrigação com o anestésico bupivacaína em alvéolos após exodontia de terceiros molares inferiores. Os autores encontraram redução significativa da dor na avaliação da EVA, mas não houve diferença entre os grupos na quantidade de analgésico consumido, de modo que os autores concluem que a irrigação dos alvéolos com o anestésico bupivacaína pode atuar como adjuvante no controle da dor pós-operatória. 
Moore et al. (1992) testaram a efetividade da aplicação de gel contendo acetominofeno ou aspirina diretamente nos alvéolos após exodontia de terceiros molares no controle da dor pós-operatória. Vinte e quatro pacientes foram incluídos no estudo e foram submetidos a exodontia de ambos os terceiros molares, com intervalo mínimo de 1 mês entre as cirurgias, em um dos lados foi utilizado o gel contendo acetominofeno ou aspirina, no outro lado apenas gel de solução salina como controle. Os autores encontraram resultados positivos na redução da dor avaliada por meio de EVA e pelo tempo entre o término da cirurgia e o uso do analgésico de resgate em ambos grupos que receberam o gel contendo analgésico.

Zandi (2008) realizou um ensaio clínico cruzado e randomizado, no qual 22 pacientes com necessidade de exodontia de ambos os terceiros molares inferiores foram divididos em 2 grupos. Um dos grupos recebeu uma dose de $8 \mathrm{mg}$ de dexametasona endovenosa 30 minutos antes do inicio da exodontia de um lado, o terceiro molar contralateral foi removido após 1 mês e serviu como controle. $O$ outro grupo recebeu em um dos lados a instalação de um dreno de borracha na região da incisão para exodontia, o qual foi mantido por 3 dias, e o lado contralateral também serviu como controle e foi removido 1 mês após. Os resultados mostraram que 0 grupo que recebeu o corticosteroide apresentou melhores resultados em relação a dor, edema e trismo comparado ao controle. Já o grupo que recebeu o dreno mostrou diminuição da dor e do trismo, mas não do edema quando comparado ao controle. Na comparação entre os grupos testes, o corticosteroide foi melhor em todos os três parâmetros analisados, sendo que o autor conclui que os benefícios da utilização de drenos não se sobrepõem aos dos corticosteroides, além de a manutenção dos drenos de borracha por 3 dias pode atrasar o processo de reparação da ferida cirúrgica.

A aplicação tópica da solução em gel contendo quitosana, clorexidina, alantoína e dexpantenol foi testada por Madrazo-Jiménez et al. (2016) com intuito de melhorar o reparo e diminuir o desconforto pós-operatório em exodontias de terceiros molares. Nesse ensaio clínico cruzado e randomizado os participantes foram submetidos à exodontia de ambos os terceiros molares inferiores, em 2 tempos cirúrgicos distintos, em um dos lados foi aplicada a solução em gel, sobre a ferida cirúrgica, 3 vezes ao dia, durante os 10 primeiros dias de pós-operatório, o lado contralateral serviu de controle. Todos foram medicados no pós-operatório com 
Amoxicilina associada ao Clavulanato e Ibuprofeno de 8 em 8 horas por 7 dias, e receberam também a prescrição de comprimidos de 500mg de Paracetamol como medicação analgésica de resgate. Não foi observada diferença significativa entre os grupos nas avaliações de dor, edema e trismo pós-operatório. Em nenhum dos grupos foi observada infecção pós-operatória, já o aspecto do reparo da ferida cirúrgica mostrou-se estatisticamente melhor no grupo teste. Os autores defendem que embora a solução testada não tenha sido eficaz no controle da dor, trismo e edema esses sintomas pós-operatórios podem ser controlados com medicações e sugerem a associação do gel testado com intuito de acelerar o reparo da ferida cirúrgica.

O uso tópico de soluções para bochecho no período pós-operatório de remoção dos terceiros molares também tem sido sugerido para redução da resposta inflamatória inerente a essas cirurgias. Eshghpour et al. (2013) estudaram a eficácia de bochechos com chá verde no controle da dor após exodontia dos terceiros molares inferiores. Em um dos lados da cirurgia os pacientes foram orientados a bochechar 2 vezes ao dia com a solução de chá verde que lhes foi entregue após a cirurgia. O dente contralateral foi removido em um segundo tempo cirúrgico, servindo como controle. Os autores encontraram redução significativa nos índices de dor medidos por meio de EVA, sendo que o grupo teste apresentou medidas de EVA estatisticamente menores que o controle, além do grupo teste ter feito uso de quantidade significativamente menor de analgésicos de resgate. Os autores concluíram que a solução de chá verde pode contribuir na redução do desconforto pós-operatório e reduzir a quantidade de medicação anti-inflamatória e analgésica necessária para controle da dor após a exodontia de terceiros molares.

Ceccheti et al. (2014) testaram o efeito analgésico e anestésico adjuvante do Tramadol aplicado pela via intraoral submucosa. Em um ensaio clínico cruzado, randomizado, duplo-cego e controlado, envolvendo 52 pacientes submetidos a exodontia de ambos os terceiros molares, em tempos cirúrgicos distintos. Após randomização, em um dos lados logo após a exodontia foi aplicada injeção submucosa de solução contendo 100mg de Tramadol, o lado contralateral serviu de controle e foi injetado solução salina. A dor foi mensurada de 4 maneiras, por meio de escala visual analógica, pelo número de comprimidos analgésicos de resgate consumidos, pelo intervalo de tempo entre o término da cirurgia e o uso do primeiro 
analgésico de resgate e pela avaliação subjetiva dos pacientes em relação à qual lado o pós-operatório foi mais doloroso. Os resultados mostraram que no lado em que foi utilizado o Tramadol o número de comprimidos analgésicos de resgate consumidos foi estatisticamente menor, o tempo entre o término da cirurgia e o uso do primeiro comprimido analgésico de resgate foi maior, a maioria dos pacientes (75\%) relatou pós-operatório mais doloroso no lado controle. Já na avaliação da EVA, na aferição realizada no momento em que cessou o efeito anestésico, quando utilizado o Tramadol a dor relatada foi estatisticamente menor, no entanto nos demais momentos de avaliação os resultados foram similares entre os grupos. Para verificar o potencial anestésico adjuvante do Tramadol foi aferido o tempo entre o início do efeito anestésico do bloqueio pterigomandibular e o momento em que os pacientes relataram a cessação da sensação de anestesia no lábio, sendo que não houve diferença entre os grupos nessa aferição. Baseado nos resultados encontrados os autores concluíram que a injeção submucosa de Tramadol é eficaz no controle da dor após exodontia de terceiros molares, mas não apresenta efeito anestésico adjuvante.

Arakeri e Brennan (2011) testaram a solução de iodopovidona (PVPI) a 0,5\% como solução de irrigação trans-operatória em exodontias de terceiros molares. Os autores avaliaram o potencial da solução em diminuir o edema pós-operatório, por meio de medidas faciais aferidas no pré-operatório, no primeiro, segundo e sétimo dias de pós-operatório. Nesse ensaio clínico foram incluídos 50 pacientes, divididos em 2 grupos, o teste que recebeu a irrigação com a solução de PVPI durante a exodontia e o grupo controle, no qual foi utilizada solução salina para irrigação transoperatória. Os resultados mostraram redução estatisticamente significativa do edema no primeiro e sétimo dias de pós-operatório comparado ao controle, no entanto no segundo dia o grupo controle apresentou menos edema, mas sem significância estatística. Baseado nos resultados, os autores afirmam que a solução se mostrou eficaz no controle do edema pós-operatório e sugerem que a mesma possa ser utilizada em outras especialidades cirúrgicas como otorrinolaringologia e cirurgia ortopédica. Sugerem ainda que o uso trans-operatório da solução de PVPI poderia substituir o uso de medicação antibiótica profilática e corticoides préoperatórios. 
Essa mesma solução de PVPI, na mesma concentração de $0,5 \%$ foi testada também por Mahmoud et al. (2015). Nesse ensaio clínico cruzado e randomizado os autores avaliaram além do edema pós-operatório, a dor e o trismo após a exodontia de terceiros molares. Os participantes tiveram ambos os terceiros molares removidos em tempos cirúrgicos distintos, de um lado foi utilizada a solução teste para irrigação trans-operatória e do outro lado o soro fisiológico como controle. No grupo teste, os resultados mostraram redução significativa do edema e do trismo avaliados no segundo e sétimo dia de pós-operatório, no entanto não houve diferença na dor pós-operatória em nenhuma das duas avaliações. 



\section{PROPOSIÇÃO}

Avaliar a eficácia da irrigação com solução de hidrocortisona $(2 \mathrm{mg} / \mathrm{ml})$ durante as exodontias de terceiros molares inferiores para o controle da dor e edema pósoperatório. 



\section{CASUÍSTICA - MATERIAL E MÉTODOS}

O presente trabalho foi aprovado pelo Comitê de Ética em Pesquisa da Faculdade de Odontologia da Universidade de São Paulo, sob o número: 1.167.908, na data de três de agosto de 2015 (ANEXO A).

Os procedimentos cirúrgicos foram realizados na Clínica de Pós-Graduação em Cirurgia e Traumatologia Bucomaxilofaciais da Faculdade de Odontologia da Universidade de São Paulo, seguindo todo o protocolo de biossegurança preconizado pela disciplina de Cirurgia Odontológica e Bucomaxilofacial. Previamente ao procedimento todos os pacientes receberam termo de consentimento livre-esclarecido (ANEXO B), o qual foi lido em conjunto com os pacientes e assinado pelos mesmos.

\subsection{Casuística}

\subsubsection{Critérios de inclusão}

- Indivíduos normorreativos, com necessidade de exodontia de ambos os terceiros molares inferiores;

- Impacções ósseas semelhantes, com a mesma classificação de inclusão dental segundo Pell e Gregory (1933), avaliadas por meio de radiografia panorâmica (ortopantomografia). 


\subsubsection{Critérios de exclusão}

- Alterações sensitivo-sensoriais;

- Uso de analgésicos ou anti-inflamatórios nas 24 horas antecedentes às exodontias;

- Gestantes ou lactantes;

- Hipersensibilidade conhecida a hidrocortisona, mepivacaína associada ao vasoconstritor corbadrina, amoxicilina e dipirona sódica.

- Pacientes com infecções pós-operatórias ou alveolites;

- Não seguimento das recomendações pós-operatórias;

- Não comparecimento às consultas pós-operatórias;

- Falha técnica na anestesia ou necessidade de utilização de mais de três tubetes anestésicos ou necessidade de utilização de diferentes quantidades de solução de irrigação;

\subsubsection{Randomização}

A randomização foi criada seguindo-se a estratégia dos números aleatórios. Uma listagem destes entre 1 e 40 foi criada por meio de programa computadorizado (Microsoft Office Excel, 2007). Admitindo-se que números ímpares receberam tratamento com a droga $A$ e os pares com a droga B. Assim, uma tabela foi desenvolvida usando-se a ordem de entrada dos pacientes no estudo, se posição par ou ímpar, para determinar qual droga - A ou B - seria administrada. Os lados também foram escolhidos aleatoriamente. Metade dos pacientes iniciou as cirurgias pelo lado direito e metade pelo esquerdo. Para assegurar o critério de estudo duplo- 
cego, um Cirurgião-Dentista alheio ao estudo determinou qual substância, soro fisiológico ou solução de hidrocortisona, seria denominada de droga A ou B na ficha de randomização dos pacientes estudados. Este profissional foi o responsável pela anotação dos dados nesta ficha até o término das cirurgias. Assim, tanto o cirurgião executante, como o paciente desconheciam a droga utilizada localmente em cada procedimento.

\subsection{Material e Métodos}

\subsubsection{Cirurgias}

As cirurgias foram realizadas por um único cirurgião, a solução anestésica utilizada foi o cloridrato de mepivacaína 2\% com corbadrina 1:20 000 (Mepi-Levo 20 - DFL $($ ), em quantidade padronizada máxima de três tubetes $(5,4 \mathrm{ml})$ para cada cirurgia. A técnica anestésica usada em todos os casos foi o bloqueio pterigomandibular, englobando os nervos alveolar inferior, bucal e lingual.

Um retalho em envelope mucoperiosteal de espessura total, com incisão intrasulcular do primeiro ao segundo molar e incisão oblíqua de alívio distal na área do trígono retromolar foi utilizado em todos os casos. Ostectomia das regiões oclusal, vestibular e distal ao terceiro molar, bem como as odontossecções coronárias e/ou radiculares foram realizadas com instrumento rotatório e brocas cirúrgicas número 702 e esféricas número 8 , conforme a necessidade cirúrgica e o planejamento prévio aos procedimentos.

A irrigação trans-operatória das cirurgias pertencentes ao grupo $H$ (hidrocortisona) foi realizada com succinato sódico de hidrocortisona $500 \mathrm{mg}$ diluído em $250 \mathrm{ml}$ de soro fisiológico $0,9 \%(2 \mathrm{mg} / \mathrm{ml})$. O lado contralateral, designado como grupo $\mathrm{C}$, controle, recebeu irrigação com $250 \mathrm{ml}$ de soro fisiológico $0,9 \%$. A solução a ser utilizada durante o procedimento cirúrgico foi sempre preparada por 
profissional alheio ao estudo, seguindo-se randomização prévia. Ambas as soluções são incolores e inodoras, com similar aparência (Figura 4.1), garantindo o critério de estudo duplo-cego.

Figura 4.1 - Soluções teste e controle

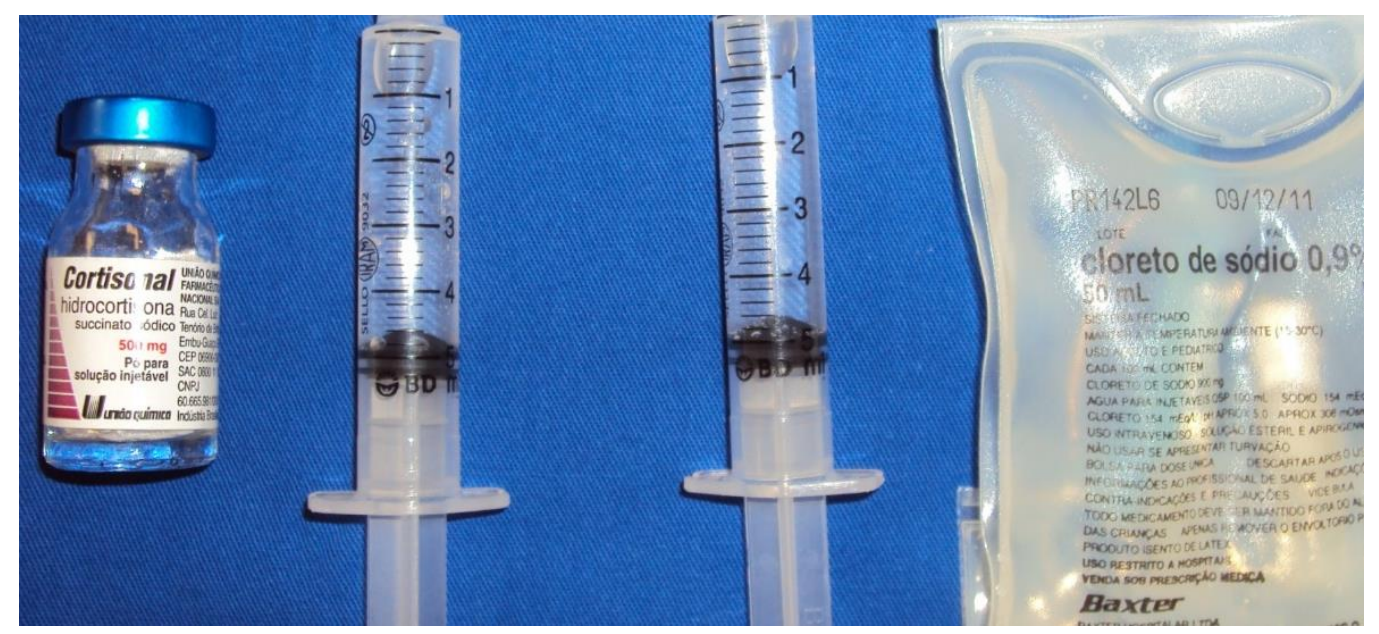

Casos com necessidade de ostectomias e/ou odontosecção receberam refrigeração/irrigação com as soluções testadas. Em casos onde não houve necessidade do uso de alta-rotação, e consequente irrigação, receberam a irrigação diretamente no alvéolo e/ou campo operatório, logo após a avulsão dental. A quantidade mínima de solução utilizada em cada paciente foi de $250 \mathrm{ml}$. Se mais solução de irrigação fosse necessária durante a primeira cirurgia de um paciente, doses incrementais de $100 \mathrm{ml}$ de solução eram utilizadas e anotadas em sua ficha, para que a mesma quantidade fosse utilizada no segundo procedimento. Caso durante a segunda cirurgia houvesse necessidade de dose maior de solução de irrigação, o paciente era excluído do estudo por apresentar diferentes quantidades de solução utilizada. 
A dificuldade de cada cirurgia foi classificada de acordo com Pozos et al. (2006):

- Grau I: exodontia com uso de fórceps ou elevadores apenas;

- Grau II: exodontia com uso de retalho mucoperiosteal e ostectomia;

- Grau III: exodontia com uso de retalho, ostectomia e secção coronária;

- Grau IV: exodontia com uso de retalho, ostectomia e odontosecção complexa (múltipla).

Os dados trans-operatórios foram catalogados em ficha própria para cada exodontia (ANEXO C).

Foi respeitado um intervalo mínimo de quinze dias (wash out) entre as cirurgias de um mesmo paciente, com intuito de evitar que a experiência de dor do primeiro procedimento influenciasse no segundo pós-operatório.

\subsubsection{Medicações prescritas}

Com intuito de padronização e evitar possíveis infecções pós-operatórias, uma vez que alguns dos pacientes apresentavam os terceiros molares semi-inclusos e história pregressa de pericoronarite, todos os participantes receberam prescrição do antibiótico amoxicilina, uma dose pré-operatória de um grama, uma hora antes do início de cada cirurgia e mantida $500 \mathrm{mg}$ a cada oito horas por sete dias. Receberam também uma prescrição do analgésico dipirona, comprimidos de $500 \mathrm{mg}$, e foram orientados a utilizar o mesmo num intervalo mínimo de 6 horas, quando houvesse dor. 


\subsubsection{Aferição da dor}

Após o término da cirurgia, os pacientes receberam as orientações pósoperatórias e um questionário (ANEXO D) no qual anotaram o horário em que perceberam a cessação do efeito anestésico, a quantidade de comprimidos de 500mg de dipirona, a medicação analgésica de resgate prescrita e a dor pósoperatória nos intervalos de tempo pré-determinados.

A dor foi mensurada por meio de uma escala visual analógica de dor (EVA), a qual foi aplicada por seis vezes no período pós-operatório. Esta é composta por uma reta de $100 \mathrm{~mm}$ de extensão, com identificação do zero em seu lado esquerdo, que representa a ausência de dor. Já na sua extremidade direita, há marcação do número 10, que representa forte presença de dor. A primeira EVA foi registrada ao término da sensação de anestesia, relatado pelo próprio paciente. As demais marcações de EVA foram realizadas em horários fixos pré-determinados de 4, 6, 8, 24 e 48 horas pós-operatórias. Além disso, o paciente anotou o dia, a hora e a quantidade de analgésicos de resgate consumidos no pós-operatório. Na mesma ficha de coleta de dados, ele pode informar outras medicações utilizadas por conta própria, o que inviabilizou sua continuidade no estudo, além de possíveis complicações pós-operatórias que apresentou, como: náuseas, vômitos, tontura, reações alérgicas e sangramento.

\subsubsection{Aferição do edema}

Com uma caneta hipodérmica, quatro pontos fixos foram marcados na face do paciente: trágus $(\mathrm{Tr})$, canto lateral do olho $(\mathrm{Co})$, comissura labial $(\mathrm{Cl})$ e ângulo goníaco (Ag). Com o paciente sentado e o plano de Frankfurt paralelo ao solo, com a posição mandibular de repouso e boca fechada, com uma fita métrica flexível foram aferidas três medidas lineares em milímetros $(\mathrm{mm})$ : do trágus à comissura labial ( $\operatorname{Tr}-\mathrm{Cl})$, do ângulo goníaco à comissura labial $(\mathrm{Ag}-\mathrm{Cl})$ e do ângulo goníaco ao 
canto do olho (Ag-Co) (Figura 4.2). Tais medidas foram realizadas previamente ao início da cirurgia e 2 dias após os procedimentos. A diferença entre as medidas do pós-operatório e do pré-operatório foi considerado o edema total.

Figura 4.2 - Reprodução esquemática dos pontos e medidas realizadas na face dos pacientes

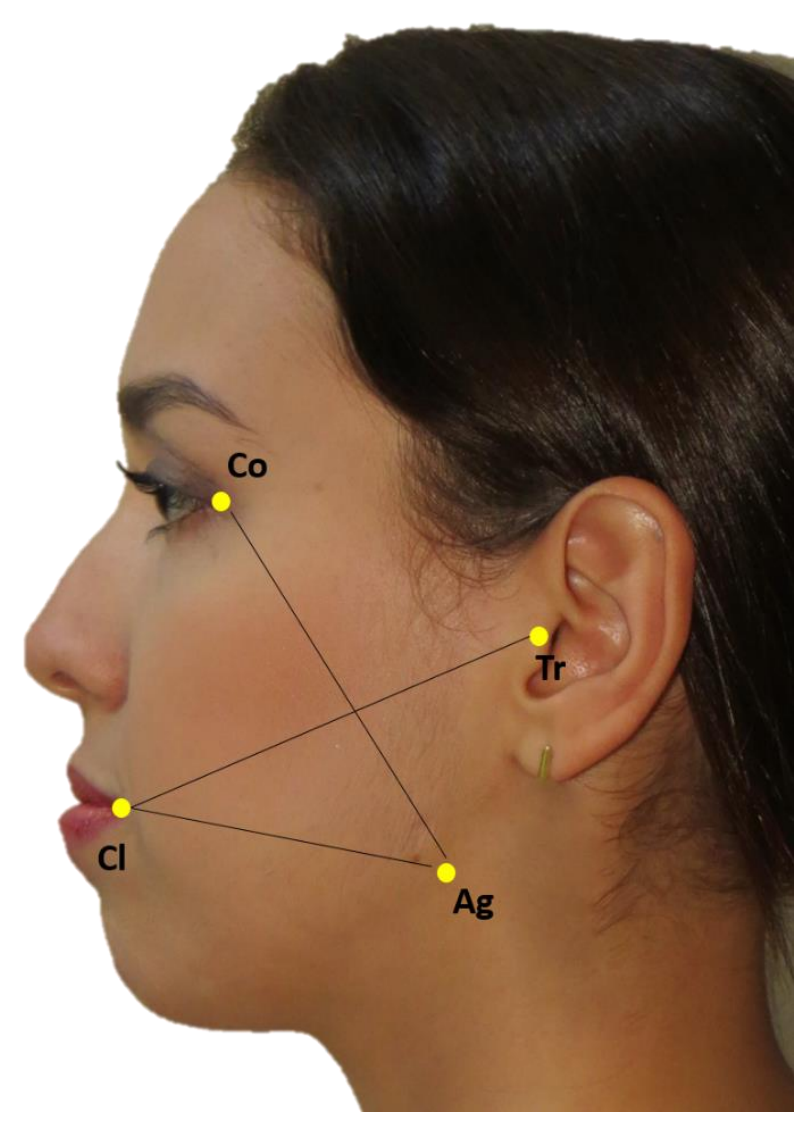

\subsubsection{Análise estatística}

As características qualitativas avaliadas foram descritas com uso de frequências absolutas e relativas, as características quantitativas foram descritas com uso de medidas resumo (média, desvio padrão, mediana, mínimo e máximo). 
A ocorrência de efeitos adversos (sangramento, náusea, vômito, tontura, reações alérgicas) e a dificuldade cirúrgica foram comparadas entre os grupos com uso de teste McNemar e teste Wilcoxon pareado, respectivamente.

As medidas de edema, bem como o tempo de cirurgia, a quantidade de dipirona e tempo até a primeira dose foram comparados entre os grupos com uso de testes de Wilcoxon pareado.

A escala de dor foi descrita segundo solução utilizada e momento de avaliação além da ordem de aplicação da solução e foram comparados os tipos de irrigação, os momentos e a ordem de aplicação com uso de Equações de Estimação Generalizadas com distribuição Normal e função de ligação identidade, supondo matriz de correlações componente simétrica entre as medidas. A análise foi seguida de comparações múltiplas de Bonferroni para comparar os níveis dos fatores dois a dois.

Para avaliar a relação entre dor e edema com a dificuldade cirúrgica foram calculadas as correlações de Spearman segundo a solução utilizada em cada cirurgia

Os testes foram realizados com nível de significância de $5 \%$. 


\section{RESULTADOS}

De um total de trinta e oito participantes, dez foram excluídos, um por apresentar parestesia no nervo alveolar inferior no pós-operatório, cinco não compareceram à consulta pós-operatória de dois dias para aferição do edema, três não retornaram para realização da segunda cirurgia e um paciente fez uso de antiinflamatório não esteroidal no primeiro dia de pós-operatório da segunda cirurgia.

Dos 28 pacientes incluídos, $20(71,4 \%)$ eram mulheres e $8(28,6 \%)$ homens. A média de idade foi de 22,9 anos, com uma variação de 14 a 54 anos. Destes, 13 $(46,4 \%)$ iniciaram a primeira cirurgia pelo lado direito e $15(53,6 \%)$ pelo lado esquerdo, essa variação se deve aos pacientes excluídos. $O$ tempo médio de intervalo entre as cirurgias foi de 48,5 dias, com mínimo de 15 dias e máximo de 190 dias (Tabela 5.1).

Tabela 5.1 - Descrição da amostra em gênero (distribuição e porcentagem), idade (média, mediana e desvio padrão), lado da primeira cirurgia (distribuição e porcentagem) e intervalo de tempo entre as cirurgias (wash out) (média, mediana e desvio padrão)

\begin{tabular}{lc}
\hline Variável & $\begin{array}{c}\text { Descrição } \\
(\mathbf{N}=\mathbf{2 8})\end{array}$ \\
\hline \hline Gênero & \\
Feminino & $20(71,4 \%)$ \\
Masculino & $8(28,6 \%)$ \\
Idade (anos) & \\
média (DP) & $22,9(7,8)$ \\
mediana (mín.; máx.) & $22(14 ; 54)$ \\
Lado da primeira cirurgia & \\
Direito & $13(46,4 \%)$ \\
Esquerdo & $15(53,6 \%)$ \\
Intervalo de tempo entre as cirurgias (wash out) & \\
média (DP) & $48,5(44,5)$ \\
mediana (mín.; máx.) & $35,5(15 ; 190)$ \\
\hline
\end{tabular}


Em relação à classificação do grau de impacção dentária, dois pacientes receberam classificação IA (7,1\%), 11 foram classificados como IIA (39,3\%), 9 como IIB (32,1\%), 4 como IIIB (14,3\%) e 2 classificados como IIIC (7,1\%). O gráfico 5.1 exemplifica a distribuição e classificação dos 56 terceiros molares entre os grupos.

$\mathrm{Na}$ avaliação trans-operatória da dificuldade cirúrgica de cada exodontia, houve o mesmo número de cirurgias de grau I (uma em cada grupo) e grau II (quinze em cada grupo). Cirurgias de grau de dificuldade III somaram 8 no grupo $\mathrm{H} \mathrm{e}$ 7 no grupo $\mathrm{C}$ e as classificadas como grau IV totalizaram 4 no grupo $\mathrm{H}$ e 5 no grupo C, não havendo diferença estatisticamente significativa entre os grupos (gráfico $5.2 \mathrm{e}$ tabela 5.2).

Gráfico 5.1 - Distribuição de impacção dental nos grupos Hidrocortisona e Controle

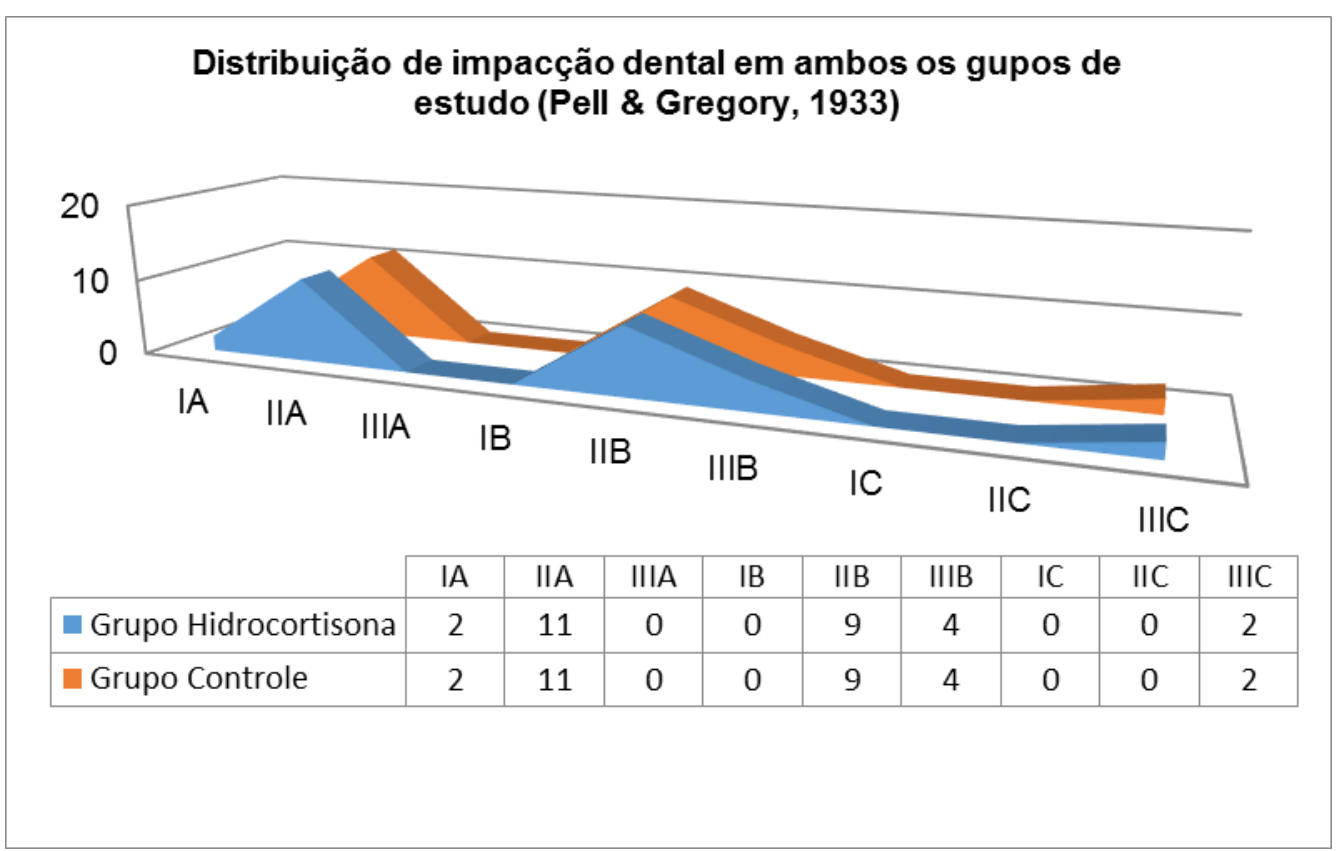


Gráfico 5.2 - Distribuição da quantidade de cirurgias entre os grupos, de acordo com a classificação de dificuldade cirúrgica

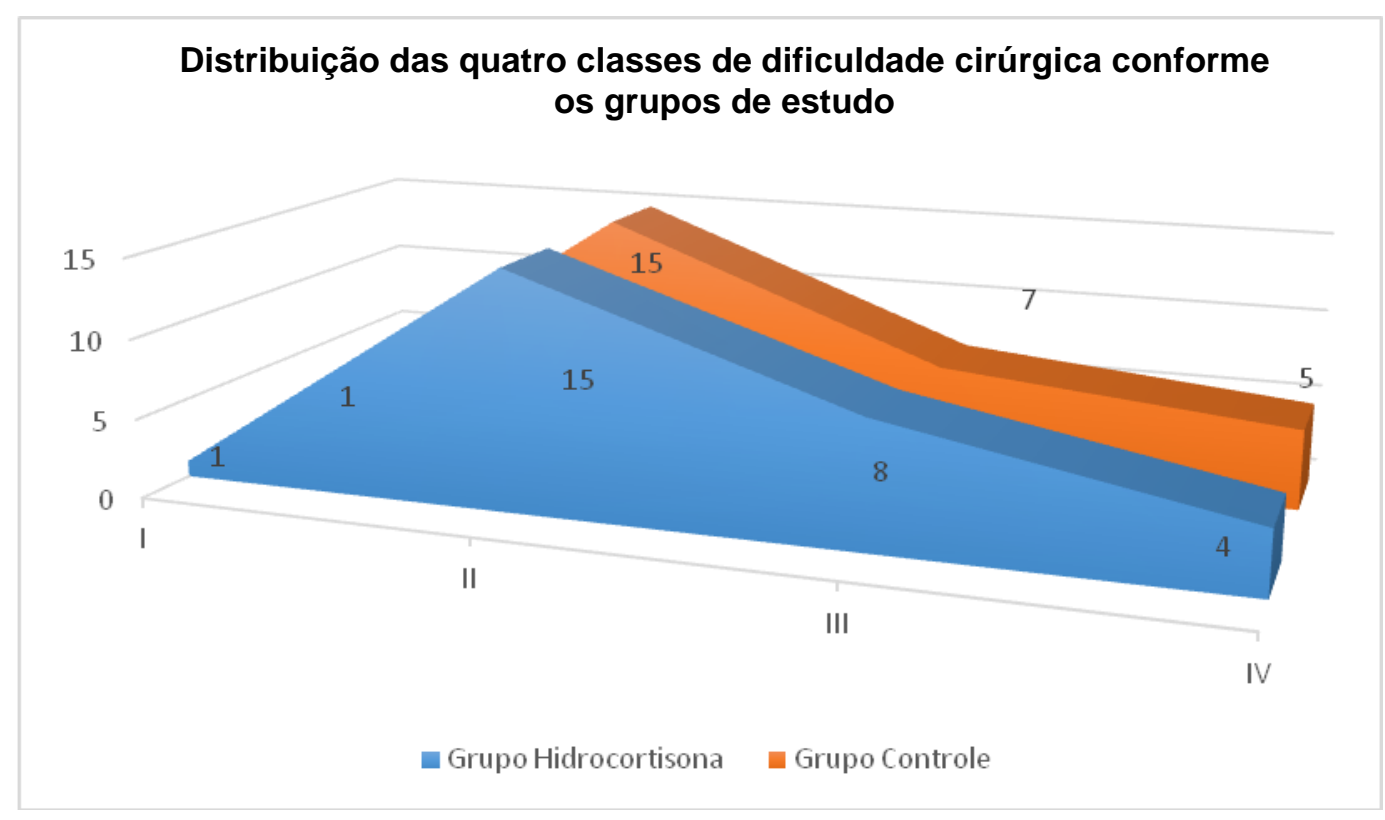

Tabela 5.2 - Descrição do grau dificuldade cirúrgica entre os grupos, e resultado do teste comparativo

\begin{tabular}{|c|c|c|c|c|c|c|c|c|c|c|c|}
\hline \multirow{3}{*}{ Escala Pozos } & \multicolumn{8}{|c|}{ Grupo C } & & & \multirow{3}{*}{$\mathbf{P}$} \\
\hline & \multicolumn{2}{|c|}{ I } & \multicolumn{2}{|c|}{ II } & \multicolumn{2}{|r|}{ III } & \multicolumn{2}{|r|}{ IV } & \multicolumn{2}{|c|}{ Total } & \\
\hline & $\mathrm{n}$ & $\%$ & $\mathrm{n}$ & $\%$ & $\mathrm{n}$ & $\%$ & $\mathrm{n}$ & $\%$ & $\mathrm{n}$ & $\%$ & \\
\hline Grupo H & & & & & & & & & & & 0.655 \\
\hline I & 1 & 3.6 & 0 & 0.0 & 0 & 0.0 & 0 & 0.0 & 1 & 3.6 & \\
\hline II & 0 & 0.0 & 14 & 50.0 & 1 & 3.6 & 0 & 0.0 & 15 & 53.6 & \\
\hline III & 0 & 0.0 & 1 & 3.6 & 5 & 17.9 & 2 & 7.1 & 8 & 28.6 & \\
\hline IV & 0 & 0.0 & 0 & 0.0 & 1 & 3.6 & 3 & 10.7 & 4 & 14.3 & \\
\hline Total & 1 & 3.6 & 15 & 53.6 & 7 & 25.0 & 5 & 17.9 & 28 & 100 & \\
\hline
\end{tabular}

Teste Wilcoxon 
O tempo médio das cirurgias do grupo $\mathrm{H}$ foi 27,32 minutos, com mínimo de 17 e máximo de 40 minutos. Sem diferença significativa quando comparada ao grupo $\mathrm{C}$, que apresentou tempo médio de cirurgia de 27,18 minutos, sendo o mínimo 18 minutos e o máximo 55 (Tabela 5.3).

Tabela 5.3 - Descrição da duração do tempo cirúrgico em minutos (média, desvio padrão, mediana, mínimo e máximo) e resultado do teste comparativo entre os grupos

\begin{tabular}{lcccccccc}
\hline Variável & Grupo & Média & DP & Mediana & Mínimo & Máximo & N & P \\
\hline \hline Duração da & $\mathrm{H}$ & 27.32 & 6.09 & 26.5 & 17 & 40 & 28 & $\mathbf{0 . 7 8 2}$ \\
cirurgia (min.) & $\mathrm{C}$ & 27.18 & 9.10 & 25 & 18 & 55 & 28 & \\
\hline
\end{tabular}

Teste Wilcoxon

pareado

O único evento adverso relatado pelos pacientes foi sangramento, não havendo diferença estatisticamente significativa entre os grupos e em nenhum dos casos houve necessidade de intervenção, todos sessaram com compressão simples com gaze, realizada pelo próprio paciente, como orientado pelo cirurgião nas recomendações pós-operatórias (Tabela 5.4)

Tabela 5.4 - Descrição da ocorrência de sangramento entre os grupos e teste comparativo

\begin{tabular}{|c|c|c|c|c|c|c|c|}
\hline \multirow{3}{*}{ Sangramento } & \multicolumn{4}{|c|}{ Grupo C } & & & \multirow{3}{*}{$\mathbf{P}$} \\
\hline & \multicolumn{2}{|c|}{ Não } & \multicolumn{2}{|c|}{ Sim } & \multicolumn{2}{|c|}{ Total } & \\
\hline & $\mathrm{n}$ & $\%$ & $\mathrm{n}$ & $\%$ & $\mathrm{n}$ & $\%$ & \\
\hline Grupo H & & & & & & & 0.453 \\
\hline Não & 17 & 60.7 & 5 & 17.9 & 22 & 78.6 & \\
\hline Sim & 2 & 7.1 & 4 & 14.3 & 6 & 21.4 & \\
\hline Total & 19 & 67.9 & 9 & 32.1 & 28 & 100 & \\
\hline
\end{tabular}

Teste McNemar 
Para aferição da efetividade da irrigação trans-operatória da solução de hidrocortisona no controle do edema pós-operatório, foram criadas 3 medidas faciais ( $\mathrm{Tr}-\mathrm{Cl}, \mathrm{Ag}-\mathrm{Cl}, \mathrm{Ag}-\mathrm{Co}$ ). O edema total foi considerado a diferença entre as medidas pós-operatórias de 2 dias (t1) e pré-operatórias (t0).

$\mathrm{Na}$ medida ângulo goníaco-comissura labial, embora a média tenha sido menor no grupo $H(6,11 \mathrm{~mm})$ em relação ao grupo $C(9,32 \mathrm{~mm})$ não houve diferença estatisticamente significativa. Nas outras duas medidas a irrigação com solução de hidrocortisona foi eficaz no controle do edema pós-operatório. A média da medida trágus-comissura labial no grupo $\mathrm{H}$ foi de $2,71 \mathrm{~mm}$ e no grupo $\mathrm{C} 8,50 \mathrm{~mm}$ com um valor de $p<0,001$. E na medida ângulo goníaco-canto do olho, o grupo hidrocortisona apresentou média de $4,29 \mathrm{~mm}$ e o controle $8,07 \mathrm{~mm}$ com $\mathrm{p}=0,034$ (Tabela 5.5).

Tabela 5.5 - Descrição da variação das medidas de edema (t1 - t0) em milímetros entre os grupos, e resultado do teste comparativo

\begin{tabular}{lcccccccc}
\hline Variável & Grupo & Média & DP & Mediana & Mínimo & Máximo & N & P \\
\hline \hline \multirow{2}{*}{$\Delta$ edema Tr-Cl } & H & 2.71 & 3.04 & 2.5 & 0 & 10 & 28 & \multirow{2}{*0,001}{} \\
& $\mathrm{C}$ & 8.50 & 5.69 & 10 & 0 & 20 & 28 & \\
\hline \multirow{2}{*}{$\Delta$ edema Ag-Cl } & $\mathrm{H}$ & 6.11 & 6.02 & 5 & 0 & 20 & 28 & \multirow{2}{*}{0.150} \\
& $\mathrm{C}$ & 9.32 & 8.52 & 6.5 & 0 & 28 & 28 & \\
\hline \multirow{2}{*}{$\Delta$ edema Ag-Co } & $\mathrm{H}$ & 4.29 & 5.96 & 2 & 0 & 25 & 28 & \multirow{2}{*}{$\mathbf{0 . 0 3 4}$} \\
& $\mathrm{C}$ & 8.07 & 8.29 & 5 & 0 & 31 & 28 & \\
\hline Teste Wilcoxon & & & & & & & &
\end{tabular}

pareado

A dor pós-operatória foi avaliada por meio de questionário (ANEXO D), no qual o paciente anotou a quantidade e os horários em que fez uso dos comprimidos analgésicos de resgate (dipirona), quantificou sua dor pela escala visual analógica (EVA) em seis momentos e respondeu, ao término das duas cirurgias, em qual lado teve o pior pós-operatório.

Dos 28 pacientes operados, $18(64,3 \%)$ afirmaram que no lado onde foi utilizado apenas o soro fisiológico (controle) o período pós-operatório foi mais desconfortável. Oito pacientes $(28,6 \%)$ relataram pior pós-operatório no lado da 
irrigação com solução de hidrocortisona e 2 pacientes disseram que não houve diferença entre os dois lados operados (Gráfico 5.3).

Gráfico 5.3 - Distribuição das respostas quanto ao pior pós-operatório entre os grupos

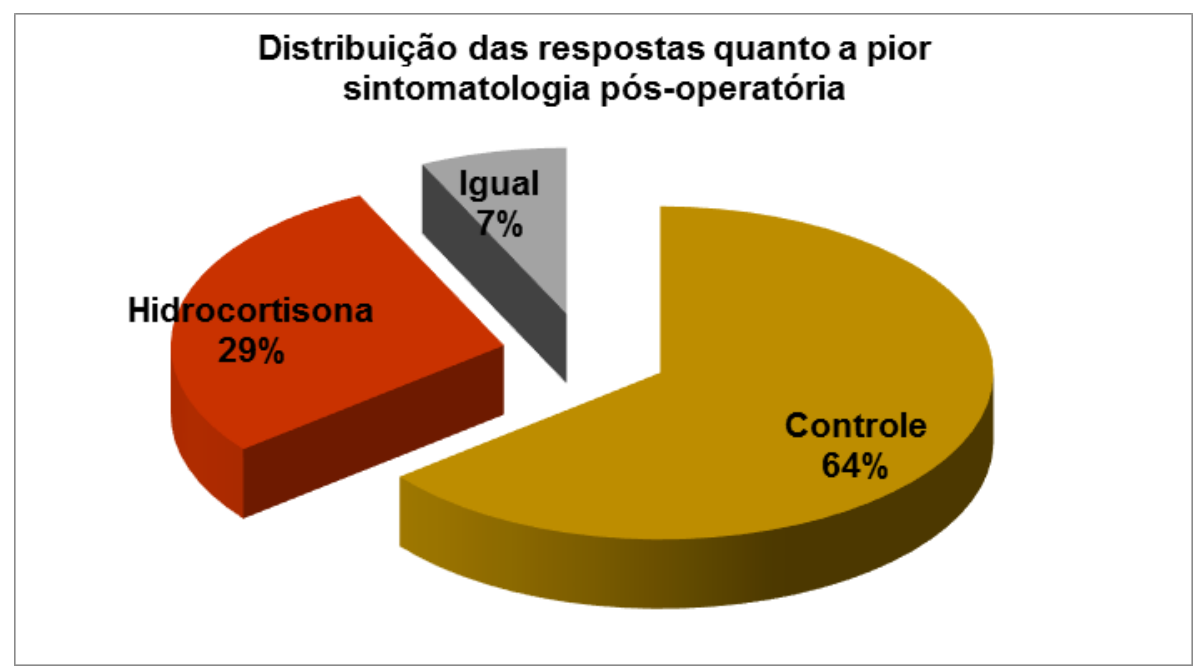

Embora no grupo $\mathrm{H}$ a quantidade média de comprimidos de dipirona consumidos $(2,9)$ tenha sido menor do que no grupo controle $(3,8)$ e o intervalo de tempo entre o término da cirurgia e o uso do primeiro analgésico tenha sido maior no grupo H (306,4min) em relação ao grupo C (266,3min), não houve diferença estatisticamente significativa na comparação entre os grupos (Tabela 5.6).

Tabela 5.6 - Descrição da quantidade de comprimidos de dipirona consumidos, intervalo de tempo entre término da cirurgia e uso da primeira dipirona e resultado do teste comparativo

\begin{tabular}{lccccccccc}
\hline \multirow{2}{*}{ Variável } & Grupo & Média & DP & Median & Mínimo & Máxim & N & P \\
\hline \hline \multirow{2}{*}{ Quantidade dipirona } & H & 2.90 & 2.20 & 3 & 0 & 7 & 28 & \multirow{2}{*}{0.308} \\
& C & 3.80 & 3.70 & 2 & 0 & 14 & 28 & \\
\hline Tempo até 1a Dipirona & H & 306,4 & 226,3 & 240 & 60 & 1140 & 25 & \multirow{2}{*}{0.317} \\
(min.) & C & 266,3 & 200,8 & 210 & 40 & 725 & 25 & \\
\hline
\end{tabular}

Teste Wilcoxon 
A avaliação subjetiva da dor por meio da EVA sugere que a média da dor foi maior no grupo $\mathrm{C}$ em relação ao grupo $\mathrm{H}$, e que a dor diminuiu ao longo dos períodos avaliados em ambos os grupos (Gráfico 5.4).

Gráfico 5.4 - Valores médios de EVA e respectivos erros padrões segundo grupo Hidrocortisona (anti-inflamatório) e Controle, momento de avaliação e ordem de aplicação (primeira cirurgia utilizado hidrocortisona ou soro fisiológico)

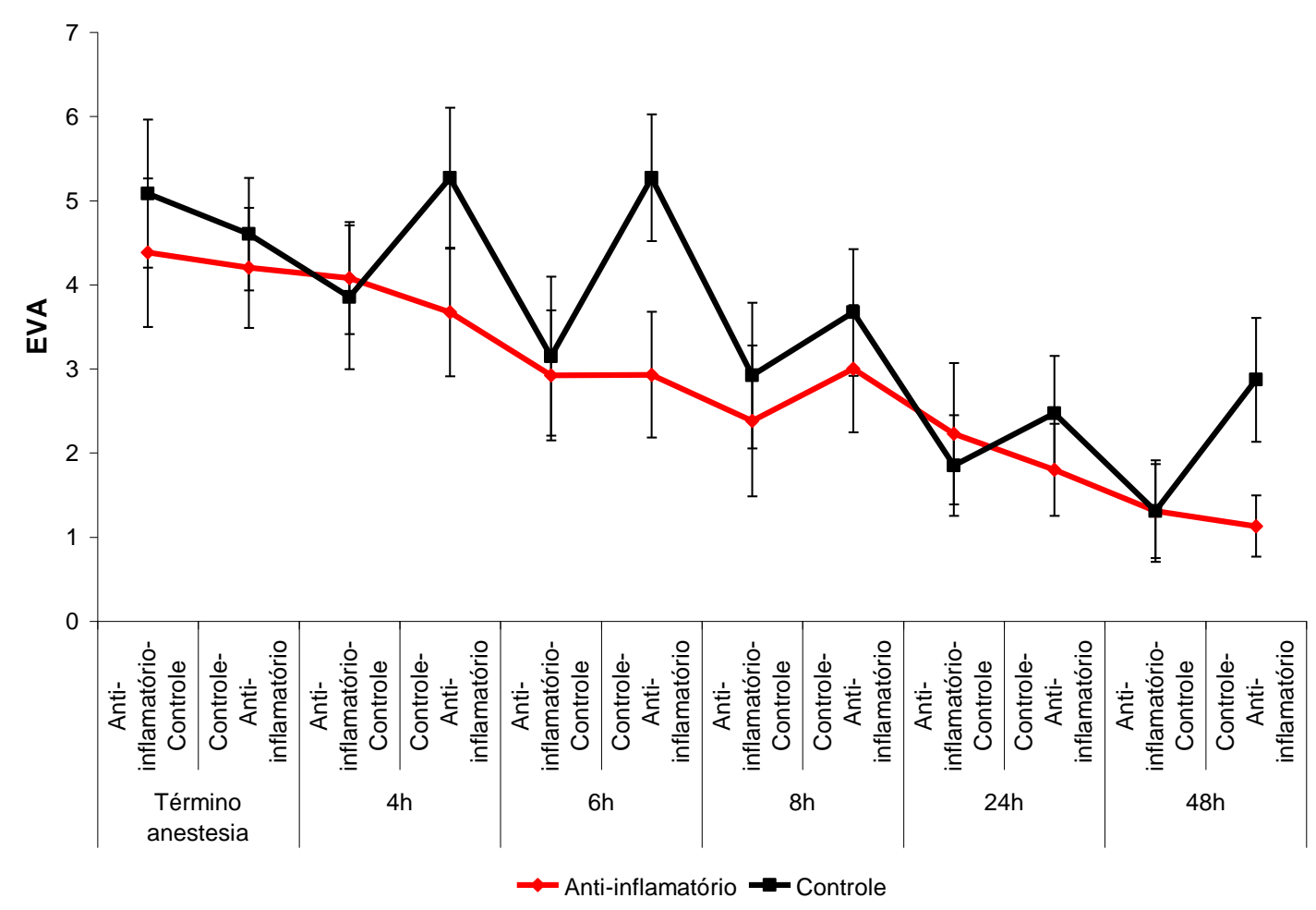

A tabela 5.7 mostra que a dor média foi estatisticamente maior no grupo Controle que no grupo Hidrocortisona $(p=0,002)$ independente do momento de avaliação e da ordem de aplicação das drogas. 
Tabela 5.7 - Comparações múltiplas da EVA entre grupos.

\begin{tabular}{cccccccc}
\hline Comparação & $\begin{array}{c}\text { Diferença } \\
\text { média }\end{array}$ & $\begin{array}{c}\text { Erro } \\
\text { padrão }\end{array}$ & $\mathbf{g l}$ & $\mathbf{p}$ & \multicolumn{2}{c}{ IC (95\%) } \\
\cline { 5 - 7 } & 0.69 & 0.23 & 1 & $\mathbf{0 . 0 0 2}$ & 0.24 & 1.13 \\
\hline \hline Controle VS Hidrocortisonar & & & & & & \\
\hline
\end{tabular}

Comparações múltiplas de Bonferroni

A associação entre dor relatada por meio da EVA, edema pós-operatório e a escala de dificuldade cirúrgica também foi verificada. Houve relação estatisticamente positiva apenas na medida de edema $\mathrm{Ag}-\mathrm{Co}$, onde quanto maior a dificuldade cirúrgica maior foi o edema, em ambos os grupos. Nas demais medidas de edema e de EVA não houve associação estatisticamente significativa (Tabela 5.8).

Tabela 5.8 - Resultado das correlações de Spearman entre a escala de dificuldade cirúrgica, EVA e edema

\begin{tabular}{lccc}
\hline Correlação & Grupo H & $\begin{array}{c}\text { Grupo C } \\
\text { Dificuldade cirúrgica }\end{array}$ & \begin{tabular}{c} 
Dificuldade cirúrgica \\
\hline \hline EVA termino
\end{tabular} \\
anestesia & $\mathrm{r}$ & -0.057 & 0.210 \\
EVA (4h) & $\mathrm{p}$ & 0.772 & 0.284 \\
& $\mathrm{r}$ & 0.312 & 0.074 \\
EVA (6h) & $\mathrm{p}$ & 0.106 & 0.709 \\
& $\mathrm{r}$ & -0.007 & 0.045 \\
EVA (8h) & $\mathrm{p}$ & 0.972 & 0.820 \\
& $\mathrm{r}$ & -0.075 & -0.015 \\
EVA (24h) & $\mathrm{p}$ & 0.704 & 0.941 \\
& $\mathrm{r}$ & 0.098 & 0.317 \\
EVA (48h) & $\mathrm{p}$ & 0.619 & 0.100 \\
$\Delta$ edema Tr-Cl (t1- & $\mathrm{r}$ & 0.215 & 0.152 \\
t0) & $\mathrm{p}$ & 0.272 & 0.440 \\
$\Delta$ edema Ag-Cl (t1- & $\mathrm{p}$ & 0.182 & 0.105 \\
t0) & $\mathrm{r}$ & 0.354 & 0.596 \\
$\Delta$ edema Ag-Co & $\mathrm{p}$ & 0.235 & 0.322 \\
(t1-t0) & $\mathrm{p}$ & 0.229 & 0.094 \\
\hline
\end{tabular}

Correlação de Spearman 


\section{DISCUSSÃO}

A cirurgia para remoção de dentes inclusos e/ou impactados é um dos procedimentos mais comumente realizados pelo Cirurgião Bucomaxilofacial, fazendo parte do seu dia-a-dia.

Todo e qualquer procedimento cirúrgico causa dano tecidual e a resposta fisiológica do corpo frente a este estímulo é o desencadeamento da cascata de inflamação, imprescindível para o reparo tecidual, mas que está acompanhada de dor e edema que podem ser de amplitude e intensidade variáveis. Diversos são os fatores que podem influenciar e modular a resposta inflamatória frente ao dano tecidual causado pela remoção de um dente incluso. Estes fatores podem estar associados ao paciente como idade, hábitos nocivos, doenças de base $\mathrm{e}$ medicações, fatores relacionados com o cirurgião, formação, experiência, habilidade e aptidão e ao próprio dente, como presença de inflamação prévia, posição e grau de impacção (Baqain et al., 2008; Bello et al., 2011). Baseado nos resultados encontrados no presente trabalho também é possível inferir que o grau de impacção é condizente com a dificuldade trans-operatória e que esta por sua vez é proporcional ao edema observado no pós-operatório, no entanto não observamos associação positiva entre a dificuldade cirúrgica e a dor relatada pelos pacientes.

A exodontia de terceiros molares tornou-se um modelo de estudo referência para ensaios clínicos, pois permite a realização de estudos cruzados, onde o paciente é o próprio controle, garantindo assim um pareamento efetivo e confiável da amostra estudada. De fato, o presente trabalho não apresentou diferenças significativas em relação a idade, tempo cirúrgico, classificação de impacção dental ou de dificuldade cirúrgica entre os grupos, evidenciando que houve pareamento eficaz da amostra e que o fato de o mesmo cirurgião ter realizado ambas as cirurgias de um mesmo paciente torna o ato cirúrgico similar, independente do lado operado, evitando possíveis vieses. 
O uso de corticosteroides em cirurgias dento-alveolares tem sido estudado desde a década de 1950, quando Spies et al. (1952) iniciaram a utilizar a hidrocortisona com intuito de melhorar o desconforto pós-operatório. Desde então vários outros corticosteroides, posologias e vias de administração foram estudadas Beirne e Hollander (1986), Graziani et al. (2006), Grossi et al. (2007), VegasBustamante et al. (2008), Antunes et al. (2011), Deo (2011), Boonsiriseth et al. (2012), Marques et al. (2014) e lbikunle et al. (2016), sempre com intuito de proporcionar um pós-operatório mais confortável aos pacientes, de forma que esses possam retornar mais rapidamente às suas atividades diárias.

Em relação à via de administração, em cirurgias dento-alveolares a mais comumente utilizada é a via oral, no entanto em pacientes com doenças gástricas como a úlcera péptica esta via pode desencadear efeitos colaterais graves. Assim as vias intramuscular, endovenosa e a injeção submucosa foram amplamente estudadas, porém mostram resultados conflitantes quanto à superioridade de uma em relação a outra.

Marques et al. (2014) estudando a injeção submucosa de betametasona no controle da dor, trismo e edema pós-operatórios não encontrou resultados positivos comparado ao controle. Enquanto que Grossi et al. (2007), estudando também a via submucosa em duas doses diferentes, $4 \mathrm{mg}$ e $8 \mathrm{mg}$ de dexametasona, observaram menor edema nos pacientes que receberam o corticosteroide, independente da concentração, mas não houve diferença significativa em relação a dor e trismo quando comparado ao controle. Os autores aplicaram também um questionário denominado de Escala de Severidade de Sintomas Pós-operatórios, no qual os pacientes apontavam e quantificavam sua percepção em relação ao desconforto após as exodontias. Os resultados mostraram que os pertencentes ao grupo controle relataram maiores alterações na aparência facial comparados aos grupos teste. No presente estudo, não aplicamos questionário específico que avaliasse a percepção dos pacientes em relação à sua qualidade de vida no período pósoperatório, no entanto os pacientes foram questionados em relação à qual lado da exodontia consideravam que o pós-operatório foi mais desconfortável e a maioria deles (64\%) afirmaram que o lado controle, onde foi utilizada irrigação apenas com SF0,9\%, o pós-operatório foi pior e apenas 2 pacientes afirmaram não ter observado diferença entre os lados operados. Embora seja uma avaliação subjetiva, a irrigação 
com o corticosteroide trans-operatório proporcionou para a maior parte dos pacientes um pós-operatório mais confortável e com menos dor.

Outros autores afirmaram que os corticosteroides usados de maneira isolada não são efetivos no controle da dor pós-operatória (Beirne; Hollander, 1986). No presente trabalho, encontramos que a irrigação trans-operatória com solução de hidrocortisona foi eficaz no controle do edema e da dor, com os resultados mostrando que na média, o grupo controle apresentou mais dor que o grupo hidrocortisona na avaliação da EVA, assim como reportado por Majid e Mahmood (2013).

A ordem na qual a solução de hidrocortisona foi utilizada influenciou na dor relatada pelos pacientes (Gráfico 5.4). Quando esta foi aplicada na primeira cirurgia os índices de EVA foram menores, o que não ocorreu na situação inversa. Assim pode-se inferir que o uso da solução de hidrocortisona na primeira cirurgia pode fazer com que o paciente se submeta ao segundo procedimento com menos ansiedade e experimente menor dor. Esses resultados são semelhantes aos observados por Ceccheti et al. (2014), que também relataram esse efeito carryover com uso de injeção submucosa de Tramadol no controle da dor após exodontias de terceiros molares.

No entanto na avaliação objetiva, medida pela quantidade de comprimidos analgésicos de resgate consumidos não encontramos diferença significativa entre os grupos, assim como não houve resultados significativos em relação ao intervalo de tempo entre o término da cirurgia e o uso do primeiro comprimido de analgésico de resgate. Resultado contrário ao observado por Deo (2011) que avaliaram a injeção submucosa de dexametasona e encontraram que, além da redução significativa do edema, o corticosteroide também prolongou a analgesia, uma vez que nos pacientes que o receberam, o intervalo de tempo entre o término da cirurgia e o uso do analgésico de resgate foi estatisticamente maior comparado ao controle. Porém os autores prescreveram Ibuprofeno para todos os pacientes, de ambos os grupos, o que pode contribuir para alteração na percepção de dor. No presente trabalho os pacientes foram orientados a utilizar somente o analgésico de resgate e não fazer uso de AINE, os que fizeram foram excluídos, justamente para que não houvesse alteração da percepção de dor pós-operatória. 
Antunes et al. (2011) compararam as vias de administração oral e intramuscular (músculo masseter) de dexametasona com um grupo controle e observou que ambos os grupos que receberam o corticosteroide apresentaram menor trismo, dor e edema comparado ao controle, no entanto não encontraram diferença nesses parâmetros entre os dois grupos teste. Os autores defendem que a aplicação intramuscular no músculo masseter apresenta como vantagem em relação ao uso oral o fato que o corticosteroide é aplicado próximo ao sítio cirúrgico, o que pode promover algum efeito local, embora não seja possível afirmar que os efeitos sistêmicos se igualem à via oral. Boonsiriseth et al. (2012) em outro estudo com metodologia similar, também avaliou a eficácia da injeção intramuscular da dexametasona, no entanto o corticosteroide foi aplicado no músculo deltoide. Os autores observaram resultados semelhantes ao de Antunes et al. (2011), fato este que pode contestar a atividade local da aplicação no músculo masseter, evidenciando que os resultados encontrados se devam mais aos efeitos sistêmicos.

Outros autores expressam a mesma opinião, de que a principal vantagem da injeção intramuscular no masseter ou a injeção submucosa seja a facilidade de aplicação, por esta ser indolor e localizada próximo ao sítio cirúrgico, sendo assim conveniente tanto para o cirurgião quanto para o paciente, além do fato de essa via de administração não depender da adesão do paciente, como na via oral. No presente trabalho a via de aplicação do corticosteroide também foi local, por meio da irrigação trans-operatória, que é indolor e inerente ao ato cirúrgico e não adiciona mais uma etapa à cirurgia apresentando resultados satisfatórios no controle da dor e edema pós-operatórios quando comparados ao controle.

Diferentes substâncias foram utilizadas como solução de irrigação em cirurgias bucomaxilofaciais, Tuffin et al. (1990) aplicaram bupivacaína em alvéolos de terceiros molares para controle da dor pós-operatória encontrando resultados positivos. Arakeri e Brennan (2011) e Mahmoud et al. (2015) utilizaram a irrigação trans-operatória com solução de iodopovidona em exodontias de terceiros molares, utilizando metodologia semelhante ao presente estudo, e também observaram menor edema no grupo teste, mas sem redução da dor pós-operatória, e assim como neste trabalho, não foram encontradas reações adversas. 
Até o presente momento, com base na literatura estudada, o único estudo além do presente trabalho, que utilizou a irrigação trans-operatória de corticosteroide diretamente no sítio cirúrgico foi o de Pourdanesh et al. (2014), sendo um estudo cruzado e randomizado com metodologia semelhante ao presente trabalho, no entanto os autores avaliaram a eficácia da irrigação trans-operatória com solução de dexametasona em osteotomias sagitais do ramo mandibular, na redução da parestesia pós-operatória e não obtiveram resultados positivos comparado ao controle.

A aplicação de corticosteroides diretamente no alvéolo após exodontia de terceiros molares já foi testada, mas em tais trabalhos o corticosteroide foi utilizado em pó e não como solução para irrigação (Majid; Mahmood, 2013). Graziani et al. (2006) testaram essa via de administração em duas doses diferentes de dexametasona, $4 \mathrm{mg}$ e $10 \mathrm{mg}$ e também a injeção submucosa de $4 \mathrm{mg}$ de dexametasona. Comparados ao controle, os três grupos testes apresentaram redução significativa do edema. Quando comparados os grupos testes entre si, não houve diferença significativa neste parâmetro. Já em relação a dor, apenas o grupo que recebeu $4 \mathrm{mg}$ de dexametasona em pó apresentou resultados estatisticamente positivos comparado ao controle. Os resultados vão ao encontro dos nossos, de modo que se pode inferir que o uso tópico trans-operatório de corticosteroides são efetivos em proporcionar um período pós-operatório em exodontias de terceiros molares mais confortável aos pacientes, além de serem de simples aplicação e não apresentaram efeitos adversos.

Os resultados que obtivemos se assemelham aos observados Majid e Mahmood (2013), que avaliaram as vias de administração oral, injeção submucosa, injeção intramuscular no deltoide, endovenosa e pó intra-alveolar de $4 \mathrm{mg}$ de dexametasona comparados ao controle. Assim como em nosso estudo, os autores observaram que os grupos testes apresentaram redução significativa do edema e da dor pós-operatória avaliada pela EVA. No entanto, em relação à quantidade de comprimidos de analgésicos de resgate consumido, antagonicamente ao presente trabalho, os autores observaram que todos grupos que receberam corticosteroides, exceto pela via oral, apresentaram um consumo estatisticamente menor de analgésicos que o controle, o que evidencia, novamente, que o uso local de 
corticosteroides é eficaz no controle do desconforto após exodontias de terceiros molares.

Baseado nos estudos revisados e nos resultados encontrados nesse trabalho é possível inferir que o uso de corticosteroides após a exodontia de terceiros molares reduz o desconforto pós-operatório, independente da via de administração, no entanto uma questão importante é o fato de a aplicação intramuscular no deltoide ou no glúteo, além de dolorida, expõe o paciente a procedimentos desnecessárias e situações desconfortáveis, e a via oral pode ser contraindicada em situações específicas como pacientes diagnosticados com doenças gástricas.

Levando-se em conta que a via endovenosa também mostra-se eficaz no controle da dor e edema pós-operatórios, a aplicação local, seja pela injeção submucosa, em pó diretamente no alvéolo ou irrigação trans-operatória teria sua principal indicação em pacientes submetidos à exodontia de terceiros molares sob anestesia local, em ambiente ambulatorial, que são a grande maioria no Brasil, tanto na prática privada quanto na esfera da saúde pública, por ser uma forma rápida, eficaz, de baixo custo, indolor e causar menos reações adversas sistêmicas quando comparados a via oral, pois em pacientes submetidos à tal procedimento sob anestesia geral, a via endovenosa, que também é eficaz no controle do desconforto pós-operatório se sobrepõe a via local por apresentar efetividade também no controle da náusea e vômito pós-operatório (Ibikunle et al., 2016).

Com base nos resultados apresentados, podemos afirmar que o uso de corticosteroides como solução de irrigação mostra-se promissor, uma vez que foi demonstrada sua eficácia na redução da dor e do edema, por ser de baixo custo, fácil aplicação e não ter apresentado reações adversas. No entanto outros estudos com metodologia semelhante devem ser realizados, avaliando outros corticosteroides e comparando-os com outras vias de administração. 


\section{CONCLUSÃO}

O estudo permitiu concluir que, o uso local do corticosteroide hidrocortisona como solução de irrigação trans-operatória foi eficaz na redução do edema após exodontia de terceiros molares e também no controle da percepção de dor pósoperatória. 



\section{REFERÊNCIAS 1}

AAOMS - American Association of Oral and Maxillofacial Surgeons. The management of impacted third molar teeth. 2013 [citado 23 set. 2016]. Disponível em: http://www.aaoms.org/images/uploads/pdfs/impacted_third_molars.pdf.

Antunes AA, Avelar RL, Martins Neto EC, Frota R, Dias E. Effect of two routes of administration of dexamethasone on pain, edema, and trismus in impacted lower third molar surgery. Oral Maxillofac Surg. 2011 DEc;15(4):217-23.

Arakeri G, Brennan PA. Povidone-iodine: an anti-oedematous agent? Int J Oral Maxillofac Surg. 2011 Feb;40(2):173-6.

Baqain ZH, Karaky AA, Sawair F, Khraisat A, Duaibis R, Rajab LD. Frequency estimates and risk factors for postoperative morbidity after third molar removal: a prospective cohort study. J Oral Maxillofac Surg. 2008 Nov;66(11):2276-83.

Beirne OR, Hollander B. The effect of methylprednisolone on pain, trismus, and swelling after removal of third molars. Oral Surg Oral Med Oral Pathol. 1986 Feb;61(2):134-8.

Bello SA, Adeyemo WL, Bamgbose BO, Obi EV, Adeyinka AA. Effect of age, impaction types and operative time on inflammatory tissue reactions following lower third molar surgery. Head Face Med. 2011 Apr;7:8.

Bhargava D, Sreekumar K, Deshpande A. Effects of intra-space injection of Twin mix versus intraoral-submucosal, intramuscular, intravenous and per-oral administration of dexamethasone on post-operative sequelae after mandibular impacted third molar surgery: a preliminary clinical comparative study. Oral Maxillofac Surg. 2014 Sep;18(3):293-6.

Boonsiriseth K, Klongnoi B, Sirintawat N, Saengsirinavin C, Wongsirichat N. Comparative study of the effect of dexamethasone injection and consumption in lower third molar surgery. Int J Oral Maxillofac Surg. 2012 Feb;41(2):244-7.

\footnotetext{
${ }^{1}$ De acordo com Estilo Vancouver.
} 
Brutin LL, Lazo JS, Parker KL. Goodman \& Gilman's the pharmacological basis of therapeutics. 11a ed. New York: McGraw-Hill; 2006.

Ceccheti MM, Negrato GV, Peres MP, Deboni MC, Naclério-Homem M G. Analgesic and adjuvant anesthetic effect of submucosal tramadol after mandibular third molar surgery. Oral Surg Oral Med Oral Pathol Oral Radiol. 2014 Mar;117(3):e249-54.

Deo SP. Effect of submucosal injection of dexamethasone on post-operative sequelae of third molar surgery. JNMA J Nepal Med Assoc. 2011 AprJun;51(182):72-8.

Eshghpour M, Mortazavi H, Mohammadzadeh Rezaei N, Nejat A. Effectiveness of green tea mouthwash in postoperative pain control following surgical removal of impacted third molars: double blind randomized clinical trial. Daru. 2013 Jul;21(1):59.

Graziani F, D'Aiuto F, Arduino PG, Tonelli M, Gabriele M. Perioperative dexamethasone reduces post-surgical sequelae of wisdom tooth removal. A splitmouth randomized double-masked clinical trial. Int J Oral Maxillofac Surg. 2006 Mar;35(3):241-6.

Grossi GB, Maiorana C, Garramone RA, Borgonovo A, Beretta M, Farronato D, et al. Effect of submucosal injection of dexamethasone on postoperative discomfort after third molar surgery: a prospective study. J Oral Maxillofac Surg. 2007 Nov;65(11):2218-26.

Ibikunle AA, Adeyemo WL, Ladeinde AL. Oral health-related quality of life following third molar surgery with either oral administration or submucosal injection of prednisolone. Oral Maxillofac Surg. 2016 Jul 22. [Epub ahead of print].

Klongnoi B, Kaewpradub P, Boonsiriseth K, Wongsirichat N. Effect of single dose preoperative intramuscular dexamethasone injection on lower impacted third molar surgery. Int J Oral Maxillofac Surg. 2012 Mar;41(3):376-9. 
Laureano Filho JR, Maurette PE, Allais M, Cotinho M, Fernandes C. Clinical comparative study of the effectiveness of two dosages of Dexamethasone to control postoperative swelling, trismus and pain after the surgical extraction of mandibular impacted third molars. Med Oral Patol Oral Cir Bucal. 2008 Feb;13(2):E129-32.

Lopes V. Third molar surgery. Br J Oral Maxillofac Surg. 1995 Dec;33(6):395-6.

Madrazo-Jiménez M, Rodríguez-Caballero Á, Serrera-Figallo MÁ, Garrido-Serrano R, Gutiérrez-Corrales A, Gutiérrez-Pérez JL, et al. The effects of a topical gel containing chitosan, $0,2 \%$ chlorhexidine, allantoin and despanthenol on the wound healing process subsequent to impacted lower third molar extraction. Med Oral Patol Oral Cir Bucal. 2016 Jul 31:0. [Epub ahead of print].

Mahmoud Hashemi H, Mohammadi F, Hasheminasab M, Mahmoud Hashemi A, Zahraei S, Mahmoud Hashemi T. Effect of low-concentration povidone iodine on postoperative complications after third molar surgery: a pilot split-mouth study. J Oral Maxillofac Surg. 2015 Jan;73(1):18-21.

Majid OW, Mahmood WK. Use of dexamethasone to minimize post-operative sequelae after third molar surgery: comparison of five different routes of administration. Oral Surg. 2013 Nov;6(4):200-8.

Marques J, Pié-Sánchez J, Figueiredo R, Valmaseda-Castellón E, Gay-Escoda C. Effect of the local administration of betamethasone on pain, swelling and trismus after impacted lower third molar extraction. A randomized, triple blinded, controlled trial. Med Oral Patol Oral Cir Bucal. 2014 Jan;19(1):e49-54.

McGrath C, Comfort MB, Lo EC, Luo Y. Changes in life quality following third molar surgery--the immediate postoperative period. Br Dent J. 2003 Mar;194(5):265-8; discussion 261.

Mettes TD, Ghaeminia H, Nienhuijs ME, Perry J, van der Sanden WJ, Plasschaert A. Surgical removal versus retention for the management of asymptomatic impacted wisdom teeth. Cochrane Database Syst Rev. 2012 Jun(6):CD003879. 
Moore UJ, Seymour RA, Rawlins MD. The efficacy of locally applied aspirin and acetaminophen in postoperative pain after third molar surgery. Clin Pharmacol Ther. 1992 Sep;52(3):292-6.

Ngeow WC, Lim D. Do Corticosteroids Still Have a Role in the Management of Third Molar Surgery? Adv Ther. 2016 Jul;33(7):1105-39.

NICE - National Institute for Health and Care Excellence. Guidance on the Extraction of Wisdom Teeth. London: NICE; 2000 [citado 23 set. 2016]. Disponível em: https://www.nice.org.uk/guidance/ta1.

Pell GJ, Gregory GT. Impacted third molars: classification and modified technique for removal. Dent Dig. 1933 Sep;39(9):330-8.

Pourdanesh F, Khayampour A, Jamilian A. Therapeutic effects of local application of dexamethasone during bilateral sagittal split ramus osteotomy surgery. J Oral Maxillofac Surg. 2014 Jul;72(7):1391-4.

Pozos AJ, Martinez R, Aguirre P, Perez J. The effects of tramadol added to articaine on anesthesia duration. Oral Surg Oral Med Oral Pathol Oral Radiol Endod. 2006 Nov;102(5):614-7.

Shaikh S, Verma H, Yadav N, Jauhari M, Bullangowda J. Applications of steroidin clinical practice: a review. ISRN Anesthesiol. 2012;2012(Article ID 985495).

Siqueira JT, Lin HC, Nasri C, Siqueira SR, Teixeira MJ, Heir G, et al. Clinical study of patients with persistent orofacial pain. Arq Neuropsiquiatr. 2004 Dec;62(4):98896.

Spies TD, Dreizen S, Stone RE, Garcia-Lopez G, Lopez-Toca R, Reboredo A. A clinical appraisal of ACTH and cortisone as therapeutic agents in dental medicine. Oral Surg Oral Med Oral Pathol. 1952 Jan;5(1):25-40.

Strean LP. The possible role of cortisone in dentistry. N Y J Dent. 1951;22:102-4. 
Tuffin JR, Cunliffe DR, Begg R, Shaw SR. Does bupivacaine irrigation of third molar sockets reduce postoperative pain? A double blind controlled trial. $\mathrm{Br} \mathrm{J}$ Oral Maxillofac Surg. 1990 Apr;28(2):96-8.

UStün Y, Erdogan O, Esen E, Karsli ED. Comparison of the effects of 2 doses of methylprednisolone on pain, swelling, and trismus after third molar surgery. Oral Surg Oral Med Oral Pathol Oral Radiol Endod. 2003 Nov;96(5):535-9.

Vegas-Bustamante E, Micó-Llorens J, Gargallo-Albiol J, Satorres-Nieto M, BeriniAytés L, Gay-Escoda C. Efficacy of methylprednisolone injected into the masseter muscle following the surgical extraction of impacted lower third molars. Int J Oral Maxillofac Surg. 2008 Mar;37(3):260-3.

Zandi M. Comparison of corticosteroids and rubber drain for reduction of sequelae after third molar surgery. Oral Maxillofac Surg. 2008 May;12(1):29-33. 

ANEXO A - Parecer do Comitê de Ética

\section{FACULDADE DE ODONTOLOGIA DA UNIVERSIDADE DE SÃO}

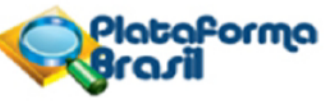

\section{PARECER CONSUBSTANCIADO DO CEP}

\section{DADOS DO PROJETO DE PESQUISA}

Título da Pesquisa: Uso tópico de hidrocortisona no controle da dor e edema pós operatório em cirurgias de terceiros molares: estudo clínico, cruzado, randomizado, duplo cego, grupo controle.

Pesquisador: Vitor Pereira Rodrigues

Área Temática:

Versão: 2

CAAE: 44657315.4 .0000 .0075

Instituição Proponente: Universidade de São Paulo - Faculdade de Odontologia

Patrocinador Principal: Financiamento Próprio

\section{DADOS DO PARECER}

Número do Parecer: 1.167 .908

Data da Relatoria: 03/08/2015

Apresentação do Projeto:

Segundo pesquisadores: "A exodontia de terceiros molares impactados é um dos procedimentos mais rotineiramente realizado pelo cirurgião bucomaxilofacial, na maior parte dos casos observa-se a presença de dor, edema e trismo no período pós-operatório, estes podem ocorrer em diferentes magnitudes. $O$ controle do desconforto pós-operatório é uma das principais preocupações do cirurgião, e diversas drogas, principalmente as com efeito antiinflamatório, foram e continuam a ser utilizadas e estudadas. Atualmente, os corticosteróides são amplamente utilizados com intuito de reduzir o desconforto pósoperatório, geralmente prescritos por via oral, mas as vias intramuscular e endovenosa foram também estudadas, assim como o uso tópico destas drogas. O objetivo do presente trabalho é avaliar a eficácia da irrigação com solução de hidrocortisona, no trans-operatório de exodontias de terceiros molares mandibulares, no controle da dor e edema pós-operatório, comparado ao grupo controle, que receberá irrigação com solução fisiológica a $0,9 \%$, afim proporcionar aos indivíduos submetidos a tal procedimento um maior conforto após as cirurgias."

"Cada paciente será submetido à exodontia de ambos os terceiros molares, assim o paciente é o proprio controle, sendo incluído tanto no grupo hidrocortisona quanto no grupo controle". Serão avaliados 40 pacientes atendidos na Clínica Odontológica da Faculdade de Odontologia da

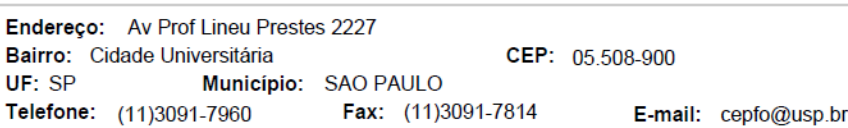




\section{FACULDADE DE ODONTOLOGIA DA UNIVERSIDADE DE SÃO}

Continuação do Parecer: 1.167.908

Universidade de São Paulo.

"O período de wash-out compreenderá um tempo mínimo de duas semanas entre as exodontias realizadas em um mesmo paciente, com o intuito de evitar vieses que possam diminuir a confiabilidade do estudo. Tratando-se de um estudo clínico cruzado, em que o próprio paciente é seu próprio grupo controle, o período mínimo de duas semanas será respeitado para que haja eliminação total da droga (hidrocortisona) caso esta seja utilizada na primeira cirurgia do paciente."

"A irrigação durante as cirurgias pertencentes ao grupo $\mathrm{H}$ (hidrocortisona) será realizada com succinato sódico de hidrocortisona $500 \mathrm{mg}$ diluído em $250 \mathrm{~mL}$ de soro fisiológico $0,9 \%(2 \mathrm{mg} / \mathrm{mL})$. O lado contralateral, designado como grupo controle, receberá irrigação com $250 \mathrm{~mL}$ de soro fisiológico $0,9 \%$."

\section{Objetivo da Pesquisa:}

Segundo os pesquisadores:

"Hipótese: A hipótese desse estudo é que a irrigação da ferida cirúrgica com o corticóide succinato de hidrocortisona tenha um efeito positivo, diminuindo o desconforto pós operatório nas exodontias de terceiros molares, especificamente em relação ao edema e à dor. Uma vez que o uso de corticoides em cirurgia oral mostra-se efetivo nas vias de administração oral e endovenosa.

Objetivo Primário: Avaliar a eficácia do uso tópico da solução de succinato de hidrocortisona durante as exodontias de terceiros molares inferiores para o controle da dor e edema pós operatório comparado-se ao controle (soro fisiológico a 0,9\%)."

\section{Avaliação dos Riscos e Benefícios:}

São citados pelos pesquisadores:

"Riscos: Levando-se em consideração os critérios de exclusão. A pesquisa apresenta riscos clínicos inerentes às cirurgias de remoção de terceiros molares inferiores, dentre os quais pode-se citar: parestesia das áreas inervadas pelos nervos alveolar inferior e lingual; fratura de mandíbula; hemorragia trans e/ou pós operatória e infecção pós operatória. Riscos estes que independem da participação da pesquisa, uma vez que serão incluídos no estudo pacientes que apresentem a indicação de exodontia de ambos os terceiros molares inferiores e esse procedimento será realizado mesmo que o paciente não participe do estudo. Caso ocorra qualquer complicação ou intercorrência os pacientes serão prontamente assistidos e todo o suporte necessário para controle e tratamento serão instituídos. O medicamente anti-inflamatório que está sendo testado

Endereço: Av Prof Lineu Prestes 2227

Bairro: Cidade Universitária

UF: SP Município: SAO PAULO

Telefone: (11)3091-7960 Fax: (11)3091-7814 E-mail: cepfo@usp.br 


\section{FACULDADE DE ODONTOLOGIA DA UNIVERSIDADE DE SÃO}

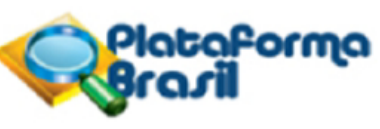

Continuação do Parecer: 1.167.908

no estudo (hidrocortisona) é amplamente utilizado pelas vias de aplicação endovenosa e intramuscular. Outros antiinflamatórios do mesmo grupo farmacológico (corticosteróides) já foram usados como irrigação trans-opertaória da ferida cirúrgica, da mesma forma que nesse estudo e não demostraram riscos e complicações advindas dessa via de administração. Alergia aos componentes da fórmula é uma contraindicação para a utilização desse medicamento, e também um critério de exclusão. Mesmo não havendo relatos, caso ocorra alguma complicação relacionada ao uso do medicamente os pesquisadores prestarão total assistência aos pacientes.

Benefícios: Os participantes podem não ter benefício direto com a pesquisa, mas se a hipótese for confirmada um novo protocolo de controle antiinflamatório

poderá ser proposto para este tipo de cirurgia odontológica. Medicações antiinflamatórias, especificamente as esteroidais (corticóides) são amplamente utilizadss em cirurgias de remoção de dentes inclusos, tanto pela via oral quanto endovenosa e seu efeito positivo na diminuição do desconforto pós operatório é bem descrito na literatura, dessa forma, acredita-se que seu uso local, trans operatório, através de solução de irrigação seja efetivo na diminuição da dor e edema após a exodontia dos terceiros molares inferiores, contribuindo para melhoria da qualidade de vida do paciente que se submete ao procedimento e permitindo que o mesmo retorne às suas atividades mais rapidamente."

\section{Comentários e Considerações sobre a Pesquisa:}

Segundo os pesquisadores: "Corticosteróides como a dexametasona e metilprednisolona tem sido amplamente utilizadas em cirurgia oral, devido ao seu menor efeito adverso sobre a quimiotaxia de leucócitos. A forma mais comum de utilização dos corticosteróides é a via oral, porém há diversos trabalhos onde aplicou-se a droga pela via endovenosa ou intramuscular, com o intuito de reduzir o desconforto pós operatório nas exodontias de terceiros molares. A utilização de drogas, principalmente as com efeito antiinflamatório, tem-se mostrado efetiva no controle do desconforto pós operatório nas cirurgias de terceiros molares, no entanto diversos outros fatores devem ser levados em consideração, como a experiência cirurgião, o grau de impacção dentária, idade do paciente e duração do procedimento, fatores que podem aumentar a incidência e intensidade das complicações."

Os pesquisadores citam 2 estudos recentes que "fizeram o uso de corticosteróides como injeção local e irrigação direto na ferida cirúrgica, sendo que ambos os estudos não relaram complicações

Endereço: Av Prof Lineu Prestes 2227

Bairro: Cidade Universitária

UF: SP Município: SAO PAULO

Telefone: (11)3091-7960_Fax: (11)3091-7814_E-mail: cepfo@usp.br 


\section{FACULDADE DE ODONTOLOGIA DA UNIVERSIDADE DE SÃO}

Continuação do Parecer: 1.167.908

advindas da aplicação local de tais medicações (Bhargava et al., 2014; Pourdanesh et al., 2014)."

\section{Considerações sobre os Termos de apresentação obrigatória:}

Apresenta:

Projeto de pesquisa no plataforma: adequado;

TCLE anexado. adequado;

Folha de rosto: adequada;

Autorização para uso da Clínica da FOUSP: adequada;

Descrição Cirúrgica Protocolo de Pesquisa;

Questionário Protocolo de Pesquisa;

\section{Recomendações:}

Tendo em vista a legislação vigente, devem ser encaminhados ao CEP-FOUSP relatórios parciais anuais referentes ao andamento da pesquisa e relatório final, utilizando-se da opção "Enviar Notificação" (descrita no Manual "Submeter Notificação", disponível na Central de Suporte - canto superior direito do site www.saude.gov.br/plataformabrasil).

Qualquer alteração no projeto original deve ser apresentada "emenda" a este CEP, de forma objetiva e com justificativas para nova apreciação.

Conclusões ou Pendências e Lista de Inadequações:

Foram realizadas as recomendações sugeridas no parecer anterior.

Situação do Parecer:

Aprovado

Necessita Apreciação da CONEP:

Não

Considerações Finais a critério do CEP:

Endereço: Av Prof Lineu Prestes 2227

Bairro: Cidade Universitária CEP: $05.508-900$

UF: SP Município: SAO PAULO

Telefone: (11)3091-7960_Fax: (11)3091-7814_ E-mail: cepfo@usp.br 


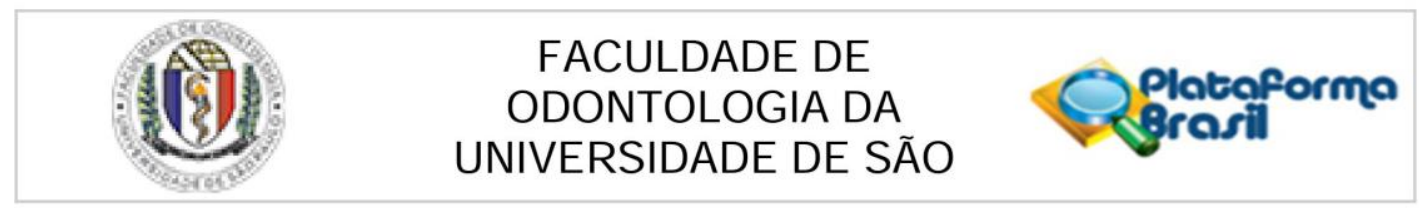

Continuaçâo do Parecer: 1.167.908

SAO PAULO, 03 de Agosto de 2015

Assinado por:

Maria Gabriela Haye Biazevic

(Coordenador)

Endereço: Av Prof Lineu Prestes 2227

Bairro: Cidade Universitária

CEP: $05.508-900$

UF: SP

Municipio: SAO PAULO

Telefone: (11)3091-7960 Fax: (11)3091-7814

E-mail: cepfo@usp.br 



\section{UNIVERSIDADE dE SÃo PAULO}

FACULDADE DE ODONTOLOGIA

TERMO DE CONSENTIMENTO LIVRE E ESCLARECIDO

DADOS DE IDENTIFICAÇÃO DO SUJEITO DA PESQUISA OU RESPONSÁVEL LEGAL

1. NOME: :

DOCUMENTO DE IDENTIDADE No: SEXO :.$M \square F \square$

DATA NASCIMENTO

ENDEREÇO

BAIRRO

CEP:.

..CIDADE

№ APTO:

2.RESPONSÁVEL LEGAL

NATUREZA (grau de parentesco, tutor, curador etc.)

DOCUMENTO DE IDENTIDADE

SEXO: $M \square F \square$

DATA NASCIMENTO.:

ENDEREÇO:

........

TELEFONE: DDD

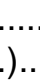

BAIRRO

CIDADE:

№

TELEFONE: DDD

APTO:

\section{DADOS SOBRE A PESQUISA}

1. Gostaríamos de convidar o(a) senhor(a) para participar da pesquisa cujo título é: Uso tópico de hidrocortisona no controle da dor e edema pós-operatório em cirurgias para remoção de terceiros molares: estudo clínico, cruzado, randomizado, duplo cego, grupo controle.

Pesquisadores: 1. Vitor Pereira Rodrigues - Cirurgião - Dentista, Especialista em Cirurgia Bucomaxilofacial (contato: 11-960372432) CARGO/FUNÇÃO: Aluno de mestrado do programa de pós-graduação em Ciências Odontológicas área de concentração em Cirurgia e Traumatologia Bucomaxilofaciais da Faculdade de Odontologia da USP.

INSCRIÇÃO CONSELHO REGIONAL DE ODONTOLOGIA: 98961. 
2. Profa. Dra. Maria da Graça Naclério-Homem - Professora Livre - Docente Associada da Disciplina de Cirurgia Odontológica e Bucomaxilofacial da Faculdade de Odontologia da USP ORIENTADORA.

3. AVALIAÇÃO DO RISCO DA PESQUISA:

RISCO MÍNIMO

RISCO BAIXO X
RISCO MÉDIO

RISCO MAIOR

\section{DESENHO DO ESTUDO E OBJETIVOS}

O objetivo deste trabalho é testar se a irrigação durante a extração dos dentes do siso de um medicamento antiinflamatório (hidrocortisona) tem efeito para controlar o inchaço e a dor após as extrações.

\section{DESCRIÇÃO DOS PROCEDIMENTOS QUE SERÃO REALIZADOS:}

Para a extração dos dentes do siso, geralmente é necessário remover o osso que recobre o dente e em alguns casos também é preciso cortar o dente para que esse possa ser removido. Durante a remoção de osso e/ou corte do dente, a broca utilizada para tal é resfriada, geralmente com soro fisiológico. Nesta pesquisa você será submetido à extração dos dentes do siso inferiores bilateralmente e um em cada consulta. Em um dos lados operado será utilizada irrigação com solução do medicamento (hidrocortisona) diluída em soro fisiológico do outro lado a irrigação será feita somente com soro fisiológico como é feito normalmente. A intenção desta pesquisa é verificar se o incômodo após a cirurgia de extração do dente, e a quantidade de medicamento via oral, pós-operatório pode ser menor quando lavamos a ferida da extração com o medicamento antiinflamatório. Antes das cirurgias você será submetido a uma radiografia panorâmica da sua boca mas não haverá custo para você. 


\section{OS DESCONFORTOS E RISCOS POSSÍVEIS E OS BENEFÍCIOS ESPERADOS}

As cirurgias para extrações de terceiros molares são realizadas sob anestesia local aplicada próxima ao dente, que provoca a sensação de dormência na região onde se localiza o dente removido, assim como na língua, lábio inferior, queixo e bochecha do mesmo lado da extração. Esta sensação dura em torno de 3 a 5 horas. Durante a extração do dente, você não sentirá dor. A extração pode levar à: inchaço no rosto do lado operado, diminuição da abertura bucal. Algumas vezes a sensação de anestesia pode durar um tempo maior que o normal no lábio inferior e língua. Esta sensação de dormência por um período além do esperado no lábio ou na língua poderá ocorrer se existir uma proximidade grande entre as raízes dos terceiros molares e o nervo na mandíbula. Apesar de pouco frequente você será informado se este risco estiver previsto. Nos casos em que ocorrer lesão destes nervos, a sensação de dormência pode ser reversível ou irreversível. Todas as medidas disponíveis para tratamento serão aplicadas. Há ainda o risco de ocorrer sangramentos que normalmente são pequenos se todas as orientações passadas pelo cirurgião dentista forem seguidas à risca. Estas orientações se referem aos cuidados que você deverá tomar no período pós operatório como a realização de compressas frias na face no primeiro dia pós operatório, dieta fria durante dois dias e líquida por uma semana, repouso físico, não realização de bochechos vigorosos durante uma semana, dormir com travesseiro alto, evitar exposição a fontes de calor, tais como permanecer próximo a fornos ou tomar banhos de sol.

O medicamente anti-inflamatório que está sendo testado no estudo (hidrocortisona) já é muito usado em várias formas de aplicação: endovenosa (aplicado na veia), intramuscular (injeção) e outros antiinflamatórios da mesma família (corticoide) já foram usados como irrigação, da mesma forma que nesse estudo e não demostraram riscos e complicações além das que podem ocorrer pelas outras formas de aplicação. Alergia aos componentes da fórmula é uma contra-indicação para a utilização desse medicamento, e também um critério de exclusão (paciente alérgico não pode participar da pesquisa). Caso ocorra alguma complicação relacionada ao uso do medicamente você terá total assistência por parte dos pesquisadores.

\section{MÉTODOS ALTERNATIVOS EXISTENTES:}

Os métodos alternativos à realização da cirurgia consistem em tratar as infecções recorrentes quando presentes através de curetagem local e uso de antibióticos. Como alternativa para a irrigação com medicamento da ferida você poderia tomar medicações via oral mas que podem aumentar o risco de alterações no estômago. 


\section{FORMA DE ACOMPANHAMENTO E ASSISTÊNCIA, ASSIM COMO OS SEUS RESPONSÁVEIS}

Você está sendo convidado de forma voluntária a participar desta pesquisa. Você será acompanhado no período pós operatório, tendo retorno ambulatorial agendado dois e sete dias após o procedimento para remoção da sutura e demais cuidados necessários. Você será orientado para, em caso quaisquer complicações advindas da cirurgia, entrar em contato com o pesquisador responsável que 0 orientará e tomará as medidas necessárias. Caso algum dano ocorra fora dos esperados, os pesquisadores desta pesquisa se responsabilizam pela execução de tratamentos adicionais quando necessários.

\section{A LIBERDADE DO SUJEITO SE RECUSAR A PARTICIPAR OU RETIRAR SEU CONSENTIMENTO EM QUALQUER FASE DA PESQUISA, SEM PENALIZAÇÃO ALGUMA E SEM PREJUÍZO AO SEU CUIDADO}

Você que decidiu participar da pesquisa poderá ser esclarecido a qualquer momento que desejar sobre o experimento. Você tem direito garantido de se recusar a participar ou retirar o seu consentimento a qualquer momento da pesquisa, sem que haja penalizações ou prejuízos ao seu tratamento.

\section{GARANTIA DO SIGILO QUE ASSEGURE A PRIVACIDADE DOS SUJEITOS QUANTO AOS DADOS CONFIDENCIAIS ENVOLVIDOS NA PESQUISA}

Os dados obtidos nesta pesquisa são sigilosos, mantendo assim a sua privacidade.

\section{FORMAS DE INDENIZAÇÃO DIANTE DE EVENTUAIS DANOS DECORRENTES DA PESQUISA}

Não há forma de indenização diante de eventuais danos decorrentes da pesquisa entretanto você terá toda assistência.

\section{ESCLARECIMENTOS DADOS PELO PESQUISADOR SOBRE GARANTIAS DO SUJEITO DA PESQUISA CONSIGNANDO:}

A. Garantia de acesso: em qualquer etapa do estudo, você terá acesso ao profissional responsável pela pesquisa para esclarecimento de eventuais dúvidas. O mestrando/pesquisador: Vitor Pereira Rodrigues, que pode ser encontrado no endereço Av. Professor Lineu Prestes, 2227, Departamento de Cirurgia e Traumatologia Bucomaxilofaciais, Cidade Universitária, CEP: 05508000, São Paulo, SP.

B. Liberdade de retirar seu consentimento a qualquer momento e de deixar de participar do estudo, sem que isto traga prejuízo à continuidade da assistência.

O Senhor (a) poderá a qualquer momento desistir de participar do estudo sem acarretar na interrupção do seu tratamento medico e ou odontológico de rotina na Instituição.

\section{Salvaguarda sigilo e privacidade.}

Os resultados de exames e o tratamento feito são sigilosos, mantendo assim a privacidade do paciente. 
9. Dúvida sobre a ética da pesquisa:

Se houver dúvidas sobre a ética da pesquisa entre em contato com o Comitê de Ética em Pesquisa em Seres Humanos da Faculdade de Odontologia - Av. Prof. Lineu Prestes 2227, 05508-000 - São Paulo, telefone (11)30917960 ou pelo e-mail cepfo@usp.br - Horário de Funcionamento: de segunda a sexta-feira das 8 às $17 \mathrm{~h}$ exceto em feriados e recesso universitário. O Comitê é um colegiado interdisciplinar e independente, de relevância pública, de caráter consultivo, deliberativo e educativo, criado para defender os interesses dos participantes da pesquisa em sua integridade e dignidade para contribuir no desenvolvimento da pesquisa dentro de padrões éticos. (Resolução CNS nº 466 de 2012).

Observação: De acordo com a resolução CNS nº466 de 2012, itens IV.3.f e IV.5.d, este termo de consentimento é elaborado em 2 vias, sendo uma retida com o pesquisador e a outra será entregue a você, devidamente assinada pelo pesquisador e seu orientador.

Eu acredito ter sido suficientemente informado a respeito das informações que li ou que foram lidas para mim, descrevendo o estudo : "Uso tópico de hidrocortisona no controle da dor e edema pós-operatório em cirurgias para remoção de terceiros molares: estudo clínico, cruzado, randomizado, duplo cego, grupo controle."

Discuti com o pesquisador Vitor Pereira Rodrigues sobre a minha decisão em participar nesse estudo. Ficaram claros para mim quais são os propósitos do estudo, os procedimentos a serem realizados, seus desconfortos e riscos, as garantias de confidencialidade e de esclarecimentos permanentes. Ficou claro também que minha participação é isenta de despesas e que tenho garantia do acesso a tratamentos adicionais associados ao procedimento realizado quando necessário. Concordo voluntariamente em participar deste estudo e poderei retirar o meu consentimento a qualquer momento, antes ou durante o mesmo, sem penalidades ou prejuízo ou perda de qualquer benefício que eu possa ter adquirido, ou no meu atendimento neste serviço.

Assinatura

do paciente/representante legal

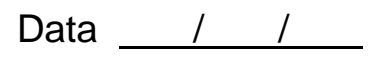

Assinatura da testemunha

Data 11

para casos de pacientes menores de 18 anos, analfabetos, semi-analfabetos.

Declaro que obtive de forma apropriada e voluntária o Consentimento Livre e Esclarecido deste paciente ou representante legal para a participação neste estudo.

Assinatura do responsável pelo estudo

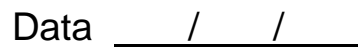



ANEXO C - Descrição Cirúrgica

\section{DESCRIÇÃO CIRÚRGICA PROTOCOLO DE PESQUISA}

Uso tópico de hidrocortisona no controle da dor e edema pós-operatório em cirurgias para remoção de terceiros molares: estudo clínico, cruzado, randomizado, duplo cego, grupo controle.

Nome:

Número de identificação do paciente:

Droga (A ou B):

Data cirurgia:

Medidas pré-operatórias:

- trágus/comissura labial:

-ângulo goníaco/comissura labial:

-ângulo goníaco/canto do olho:

Horário início da cirurgia:

Horário do término cirurgia:

Número do dente:

Classificação de Pell e Gregory:

Tipo de incisão utilizada:

Realizou-se Odontosecção?

Sim Não

Realizou-se Osteotomia?

Sim

Não

Quantidade de anestésico utilizado:

tubetes

Anestésico local utilizado:

Intercorrências no trans-operatório:

Sim

Não

Descrição da intercorrência:

Tempo de duração da cirurgia:

Complicações pós operatórias:

Sim

Não

Descrição:

Medidas pós-operatórias:

48 horas após cirurgia:

-trágus/comissura labial:

-ângulo goníaco/comissura labial:

-ângulo goníaco/canto do olho: 

ANEXO D - Questionário

\section{QUESTIONÁRIO PROTOCOLO DE PESQUISA}

Uso tópico de hidrocortisona no controle da dor e edema pós-operatório em cirurgias para remoção de terceiros molares: estudo clínico, cruzado, randomizado, duplo cego, grupo controle.

Nome:

Idade:

Sexo:

Data cirurgia: Horário início cirurgia:

Horário de termino da cirurgia:

Horário em que passou a anestesia:

Quantifique a dor que você sente no momento, em uma escala de 0 a 10, na qual a nota zero corresponde a nenhuma dor e a nota 10 corresponde à máxima dor que você já sentiu.

No momento em que passou a anestesia:

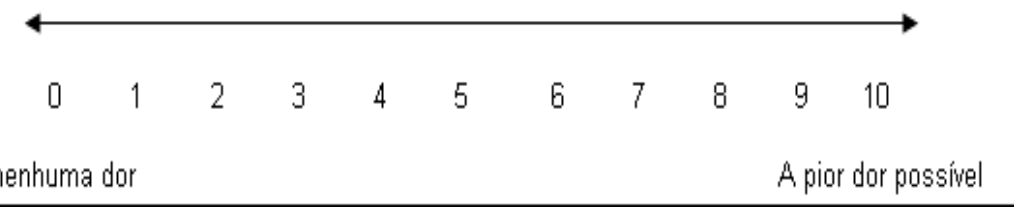

Quatro horas após o término da cirurgia:

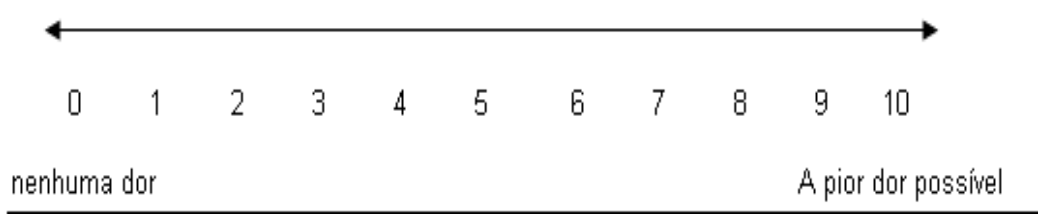

Seis horas após o término da cirurgia:

$\begin{array}{ccccccccccccc} & 1 & 2 & 3 & 4 & 5 & 6 & 7 & 8 & 9 & 10 \\ \\ \text { nenhuma dor }\end{array}$


Oito horas após o término da cirurgia:

$\begin{array}{llllllllllll} & & 1 & 2 & 3 & 4 & 5 & 6 & 7 & 8 & 9 & 10 \\ \text { nenhuma dor } & & & & & & & & & \text { A pior dor possivel }\end{array}$

Vinte e quatro horas após o término da cirurgia:

$\begin{array}{lllllllllllll} & 4 & 1 & 2 & 3 & 4 & 5 & 6 & 7 & 8 & 9 & 10 \\ \text { menuma dor } & & & & & & & & & & & \text { A pior dor possivel }\end{array}$

Quarenta e oito horas após o término da cirurgia:

\begin{tabular}{ccccccccccccc}
\hline & 1 & 2 & 3 & 4 & 5 & 6 & 7 & 8 & 9 & 10 \\
nenhuma dor & & & & & & & & A pior dor possivel \\
\hline
\end{tabular}

Caso tenha precisado tomar medicação analgésica (Dipirona sódica $500 \mathrm{mg}$ ) para controle de dor após a cirurgia, anote abaixo todas as vezes que tomou, o dia e o horário:

\begin{tabular}{|l|l|l|}
\hline Medicação & Dia & Horário \\
\hline & & \\
\hline & & \\
\hline & & \\
\hline & & \\
\hline & & \\
\hline & & \\
\hline & & \\
\hline & & \\
\hline
\end{tabular}


Você fez uso de alguma outra medicação analgésica além daquela prescrita pelo cirurgião dentista que realizou sua cirurgia?

Qual foi esta medicação e quando foi tomada?

Você sentiu algum desses sintomas após a cirurgia? (sangramento, tontura, náusea, vômito, reações alérgicas) - descreva:

Assinatura do sujeito da pesquisa

Assinatura do pesquisador 